\title{
Polycation-PEG Block Copolymer Undergoes Stepwise Phase Separation in Aqueous Triflate Solution
}

\section{Baddam, Vikram}

2018-12-11

Baddam , V , Aseyev , V , Hietala , S, Karjalainen , E \& Tenhu , H 2018 , ' Polycation-PEG Block Copolymer Undergoes Stepwise Phase Separation in Aqueous Triflate Solution ' , Macromolecules, vol. 51 , no. 23 , pp. 9681-9691 . https://doi.org/10.1021/acs.macromol.8b01810

http://hdl.handle.net/10138/323326

https://doi.org/10.1021/acs.macromol.8b01810

acceptedVersion

Downloaded from Helda, University of Helsinki institutional repository.

This is an electronic reprint of the original article.

This reprint may differ from the original in pagination and typographic detail.

Please cite the original version. 


\title{
Polycation-PEG block copolymer undergoes step-wise phase separation in
}

\section{aqueous triflate solution}

Vikram Baddam, Vladimir Aseyev, Sami Hietala, Erno Karjalainen and Heikki Tenhu*

Department of Chemistry, PB 55, FIN-00014 University of Helsinki, Finland

\begin{abstract}
A block copolymer poly(ethylene glycol)-b- poly(vinylbenzyltrimethyl ammonium triflate), PEG-PVBTMA-OTf, and a homopolymer PVBTMA-OTf were synthesized through RAFT reactions. The polymers were studied in aqueous triflate solutions with varying temperatures, changing also the polymer and salt concentrations. The hydrophobic triflate anion turns polycations thermoresponsive and they show an UCST. In the block copolymer, the interaction between the PEG and the cationic block makes the phase separation occur in distinct steps. Upon cooling, transparent solutions first turn turbid and then, partially clear at $T_{c L}$. The $T_{C L}$ is not observed in a mixed solution of PVBTMA-OTf and PEG macroCTA. By considering the interplay between ionic, hydrogen bonding, and hydrophobic interactions an overall picture of the complex phase separation processes is suggested.
\end{abstract}

*Corresponding author

heikki.tenhu@helsinki.fi, Department of Chemistry, University of Helsinki, PB 55, FIN-00014, Finland. Introduction

There are two types of aqueous thermoresponsive polymers, i.e. those phase separating upon heating above the lower critical solution temperature LCST and those phase separating when cooled, at the upper critical 
solution temperature UCST. Aqueous polymers with a LCST have been thoroughly studied ${ }^{1,2}$ but the interest on the aqueous polymers with an UCST has recently considerably increased. ${ }^{3-6}$

The polymers with an UCST may be either chargaed or non-charged. In the case of the charged polymers, polyelectrolytes, the UCST owes to multiple interactions between the polymer chains: ionic, hydrogen bond, and hydrophobic interactions. The non-charged polymers interact through $\mathrm{H}$-bonding and hydrophobic interactions. Whereas the hydrophobic interactions dominate upon heating, increasing thermal energy breaks the ionic and H-bonds thus leading to the dissolution of the polymer at the UCST. ${ }^{7}$

Several polycations have been observed to show thermoresponsive behavior under certain conditions. Their solubility can be tuned by changing the counter ion. Depending on the counter ion, the polymer may be totally (in)soluble in water or may dissolve when heated, at the UCST.$^{8-12}$ Recent studies on the UCST behavior of poly (2-(methacryloyloxy)ethyltrimethylammonium iodide) (PMOTAI) and poly(3-methyl-1-(4vinylbenzyl)imidazolium chloride) polycations with bis(trifluoromethylsulfonyl)amide (NTf $f_{2}$ or trifluoromethanesulfonate (OTf) as counter ions have revealed that a hydrophobic counter ion can induce the UCST behavior. An important finding is that in order to observe the cloud /clearing point a sufficient ionic strength is required. The necessary ionic strength may be introduced either with the hydrophobic salt or other added electrolytes. ${ }^{13}$

While the number of studies on polymers with UCST is increasing, it is quite natural that chemists have started to synthesize also polymers with coexisting UCST and LCST. ${ }^{14-19}$ Polymers with a certain solubility window are considered useful for certain applications, as, e.g., carriers of active substances. ${ }^{20,21} \mathrm{~A}$ few reports may be found on random copolymers with both UCST and LCST while most of these are on block copolymers. ${ }^{22,23}$ What comes to the UCST polymers, probably the most common of these are non-ionic ones, the solution properties of which are governed in water mainly by intra and inter molecular hydrogen bonds. Zwitterionic polymers often show UCST, ${ }^{4,24}$ as well as some polyampholytes. ${ }^{25,26}$ Both UCST and LCST has been observed for PEG-polyzwitterion 
block copolymers. ${ }^{27}$ Block copolymers of PEG and poly(dimethylaminoethylmethacrylate) undergo both UCST and LCST transitions in the presence of trivalent counterions. ${ }^{28}$

In the present work, block copolymers which comprise of a poly(ethylene glycol) block connected to a polycation have been synthesized. The rationale behind choosing the PEG-based polycations for subject of study was, firstly, the expected UCST-type behavior of the polycation and secondly, the fact that PEG is normally well soluble in water at all temperatures below $100^{\circ} \mathrm{C}$. Pegylation is a widely used method to stabilize various entities in water. PEG macro-CTA (see Scheme 1) was used as a chain transfer agent, the synthesis giving PEG-PVBTMA-OTf as a product. Owing to the synthesis method there is a short alkyl chain in the end of the cationic block. For comparison a homopolymer PVBTMA-OTf was prepared as well. In the homopolymer synthesis, 2-cyano-2-propyl dodecyl trithiocarbonate was used as the chain transfer agent and thus, both polymers carry the same short alkyl chains in their ends. Hydrophobes tend to increase the UCST but in the present case the effect is the same with both polymers. The triflate (trifluoromethanesulfonate) counter ion was in preliminary experiments observed to create a polymer with an UCST in a measurable temperature range. The choice of PVBTMA was justified by firstly the fact we have investigated the solubilities of various polycations and observed the complex diversity in their phase behavior. ${ }^{13,23}$ PVBTMA may be regarded a polymeric ionic liquid and thus, it will probably find several applications. As a polycation it may be applied in biomedical, catalysis and energy fields. ${ }^{29-32}$

We report on properties of both the homopolymer PVBTMA-OTf and the block copolymer PEG-PVBTMA-OTf in aqueous solutions of lithium triflate. The phase separations to be discussed were not observed in pure water. The homopolymer shows UCST in water in the presence of salt, whereas the block copolymer shows consecutive cloud and clearing points $\left(T_{c \cup}\right.$ and $\left.T_{c L}\right)$ within a certain range of ionic strength. Interestingly, the clouding and clearing of the systems are complicated and take place in steps. We try to rationalize these in terms of the interactions between the cationic and the PEG blocks, as well as of those between the OTf ion and the polymers. In addition, we have observed that a prerequisite for the coexistence of the $T_{c u}$ and $T_{C L}$ is that the two blocks are covalently linked. In a mixed solution of PVBTMA-OTf and PEG macroCTA, only the UCST is observed. Overall, the 
aqueous polymer-salt solutions to be discussed turned out to be complicated. Or, in other words, we try to show the multiple possibilities to fine tune the properties of these systems.

\section{Experimental}

\section{Materials}

(Vinylbenzyl)trimethylammonium chloride [(VBTMA)Cl; 99\%)], 4,4'-azobis(4-cyanovaleric acid) (ACPA; $275 \%)$ were recrystallized from methanol while 2-cyano-2-propyl dodecyl trithiocarbonate (CPDTC; 97\%, Sigma) was used as received. Trifluoromethanesulfonic acid lithium salt (LiOTf; 99.995\%), sodium formate (HCOONA; $\geq$ 99.0\%), and poly(ethylene glycol) methyl ether 2-(dodecylthiocarbonothioylthio)-2-methylpropionate (PEG macroCTA; average $\mathrm{M}_{\mathrm{n}} 5,000 \mathrm{~g} \mathrm{~mol}^{-1}$ ) were used as received from Sigma. Methanol (Fluka), acetone (Honeywell) were used as received, and acetonitrile (Fluka) was distilled over $4 \AA$ molecular sieves. Deionized water was purified with ELGA purelab ultrapurification system. Distilled water was used in the dialysis. Dialysis tubings of regenerated cellulose from Orange Scientific, with the molecular weight cutoff of 5000-8000 $\mathrm{g} \mathrm{mol}^{-1}$ were used for purification of polymers.

\section{Syntheses}

The monomer (vinyl benzyl) trimethylammonium trifluoromethanesulfonate (VBTMA-OTf) was obtained by counter ion exchange conducted in acetonitrile (see the Supporting Information). Both the homo and block copolymers were obtained via aqueous RAFT polymerization. The polymerizations were thermally initiated with

a water soluble azo based initiator ACPA (see Supporting Information). The RAFT polymerizations were conducted with reagent ratios [monomer]: [CTA]: [ACPA] of 100: 1: 0.2. 


\section{Sample preparation}

All the samples were prepared with a similar protocol. Initially, polymer stock solutions with concentrations of $20 \mathrm{mg} \mathrm{mL}^{-1}$ or $10 \mathrm{mg} \mathrm{mL}^{-1}$ were prepared. The solutions were shaken at room temperature overnight before sample preparation. To prepare the samples, a salt solution was first made to the vials and next, a needed amount of the stock solution was added. A detailed procedure to prepare a sample with $50 \mathrm{mM}$ LiOTf and $1 \mathrm{mg}$ $\mathrm{mL}^{-1}$ polymer was as follows. First, $150 \mu \mathrm{L}$ of $1 \mathrm{M}$ LiOTf solution was diluted with $2550 \mu \mathrm{L}$ of water and stirred vigorously. Next, $300 \mu \mathrm{L}$ of $10 \mathrm{mg} \mathrm{mL}^{-1}$ polymer solution was added.

\section{${ }^{1} \mathrm{H}$ NMR spectroscopy}

The degree of polymerization and molecular mass $\left(M_{n}\right)$ of the polymers were determined with end group analysis by ${ }^{1} \mathrm{H}$ NMR spectroscopy using a Bruker Avance III $500 \mathrm{MHz}$ spectrometer (10 mg mL ${ }^{-1}$ polymer samples in DMSO$\left.d_{6}\right)$. The temperature dependence of the NMR spectral intensities was measured in $D_{2} O$. In these measurements the polymer concentration was $2 \mathrm{mg} \mathrm{mL}^{-1}$ with $50 \mathrm{mM}$ LiOTf and $1.47 \mathrm{mM}$ of HCOONa. Sodium formate or the solvent signals were used as a reference when integrating the intensities of the lines. The measurements were conducted by cooling from 60 to $20^{\circ} \mathrm{C}$.

\section{Transmittance}

The transmittance of the solutions was measured as a function of temperature with a JASCO J-815 CD spectrometer equipped with a PTC-423S/15 Peltier temperature control system or with JASCO V-750 UV-Visible spectrophotometer equipped with a JASCO CTU-100 thermostat system. The transmittance was measured at $600 \mathrm{~nm}$ wavelength. Temperatures were measured directly from the sample while controlling the temperature with the sample holder. The heating and cooling rates were $1^{\circ} \mathrm{C} \mathrm{min}^{-1}$. 
Prior to the measurements the sample solutions were degassed in vacuum below $10^{\circ} \mathrm{C}$. The experiments were typically conducted by heating the sample to elevated temperature and stabilizing for 10 minutes. The solutions turned transparent within this period. Then the measurement followed by cooling the holder stepwise to around $10^{\circ} \mathrm{C}$. Next a heating cycle was measured, with 10 minutes of an initial stabilization at the starting temperature.

\section{Differential scanning micro calorimetry (micro-DSC)}

Micro-DSC measurements were conducted with a Malvern MicroCal PEAQ DSC micro calorimeter. Prior to the measurements, the cells were stabilized at $80^{\circ} \mathrm{C}$ for 10 minutes. The measurements were done by cooling the cells from 80 to $10{ }^{\circ} \mathrm{C}$ with a cooling rate $1{ }^{\circ} \mathrm{C} \mathrm{min}-1$. Then the reversibility of the transition was studied with controlled heating. First, sample was stabilized at $10{ }^{\circ} \mathrm{C}$ for 10 minutes, then heating it to $80^{\circ} \mathrm{C}$ with heating rate $1{ }^{\circ} \mathrm{C} \mathrm{min}-1$. The polymer concentrations of the samples varied from 0.5 to $3.5 \mathrm{mg} / \mathrm{ml}$ (in $50 \mathrm{mM}$ LiOTf solution) The effects of varying heating rates were studied on a sample with polymer concentration $2 \mathrm{mg} \mathrm{mL}^{-1}$.

\section{Dynamic light scattering (DLS)}

Two types of instrumentation were used. The temperature dependent intensities and size distributions of the polymer solutions were studied with Malvern Instruments ZetaSizer Nano-ZS equipped with a $4 \mathrm{~mW}$ He-NE laser operating at $633 \mathrm{~nm}$. Hydrodynamic diameters were measured at $173^{\circ}$. Measurements were carried out in the temperature range $70-20{ }^{\circ} \mathrm{C}$. The samples were allowed to equilibrate for $3 \mathrm{~min}$ at each temperature. Hydrodynamic diameter is given by intensity and intensity is given as counts of photons per second.

The angular dependence of the scattered light intensity was measured using a Brookhaven instrument BI-200SM goniometer, BIC-TurboCorr digital pseudo-cross-correlator and BI-CrossCorr detector including two BIC-DS1 detectors. Pseudo-cross-correlation functions were collected in a self-beating method. Light source was BI-mini L140 at $637 \mathrm{~nm}$, operated with 50\% power, this giving incident light of $70 \mathrm{~mW}$. All measurements were conducted 
on samples with $2 \mathrm{mg} \mathrm{mL}^{-1}$ polymer and $50 \mathrm{mM}$ LiOTf. The samples were filtered into the cuvettes with $0.45 \mu \mathrm{m}$ Millipore PVDF filters.

\section{Results and discussion}

\section{Syntheses}

The syntheses of the polymers were started by changing the chloride ion on the VBTMA monomer into OTf. The monomer was characterized with ${ }^{19} \mathrm{~F}$ NMR which confirmed the presence of the OTf counter ion (Figure S1). The syntheses of both homo and block copolymers were conducted in water- methanol mixtures with identical ratios of the monomer and CTA (Scheme 1). The reaction mixtures were clear at elevated temperature but turned cloudy when cooled to room temperature, this indicating the thermoresponsive character of the polymers.

The conversions of the polymerizations were calculated from the integrals of the aromatic and vinyl protons in the ${ }^{1} \mathrm{H}$ NMR spectra taken from the reaction mixtures. The molar masses of the polymers were determined from the NMR spectra in DMSO- $\mathrm{d}_{6}$ by end group analysis for the PVBTMA-OTf homopolymer using the $-\mathrm{CH}_{3}$ from the aliphatic hydrocarbon chain as a reference. The $\mathrm{CH}_{2}$ signals of the $\mathrm{PEG}$ repeating units were taken as reference in the case of the block copolymer. The proton spectra are shown in Figure S2.

The details of the reaction conditions and the polymer molar masses are given in Table 1. Size exclusion chromatography (SEC) was conducted for both polymers in with water/ $\mathrm{NaNO}_{3}$ and in $\mathrm{DMF} / \mathrm{LiBr}$ as eluents. These measurements did not give any result because of either too low solubility of the polymers or adsorption to the columns.

Table1. Syntheses of homo and diblock copolymers of VBTMA-OTF 


\begin{tabular}{|c|c|c|c|c|c|c|}
\hline Polymer & [M]:[CTA]:[I] & $\begin{array}{l}\text { Conversion of } \\
\text { VBTMA-OTf }\end{array}$ & $\begin{array}{l}\text { DP(NMR) } \\
\text { (VBTMA- } \\
\text { OTf) }\end{array}$ & $\begin{array}{c}\text { Mn (theo) } \\
\text { PVBTMA)- } \\
\text { OTf) }^{b}\end{array}$ & $\begin{array}{c}\mathrm{Mn}_{\mathrm{n} \text { (NMR) }} \\
\text { PVBTMA-OTf }\end{array}$ & $\begin{array}{c}M_{n} \text { (NMR) } \\
\text { PEG-PVBTMA- } \\
\text { OTf }\end{array}$ \\
\hline PVBTMA-OTf & 100:1:0.2 & $90 \%$ & 60 & 30000 & 20100 & - \\
\hline PEG-PVBTMA-OTf & $100: 1: 0.2$ & $97 \%$ & 81 & 36500 & 23400 & 30700 \\
\hline
\end{tabular}

${ }^{a}$ The monomer conversion determined from NMR-spectra. ${ }^{\mathbf{b}}$ The theoretical molecular mass obtained from the equation $[M] /[C T A] \times$ conv. $\times M_{M}+M_{C T A} . M_{n}$ of the macro-CTA $5000 \mathrm{~g} / \mathrm{mol}$ according to the supplier, $M_{n}$ from SEC is $4900 \mathrm{~g} / \mathrm{mol}$ with PDI 1.01, from ${ }^{1} \mathrm{H}$ NMR average DP is 93 ). ${ }^{\mathrm{c}}$ The molecular mass determined by ${ }^{1} \mathrm{H}$ NMR.

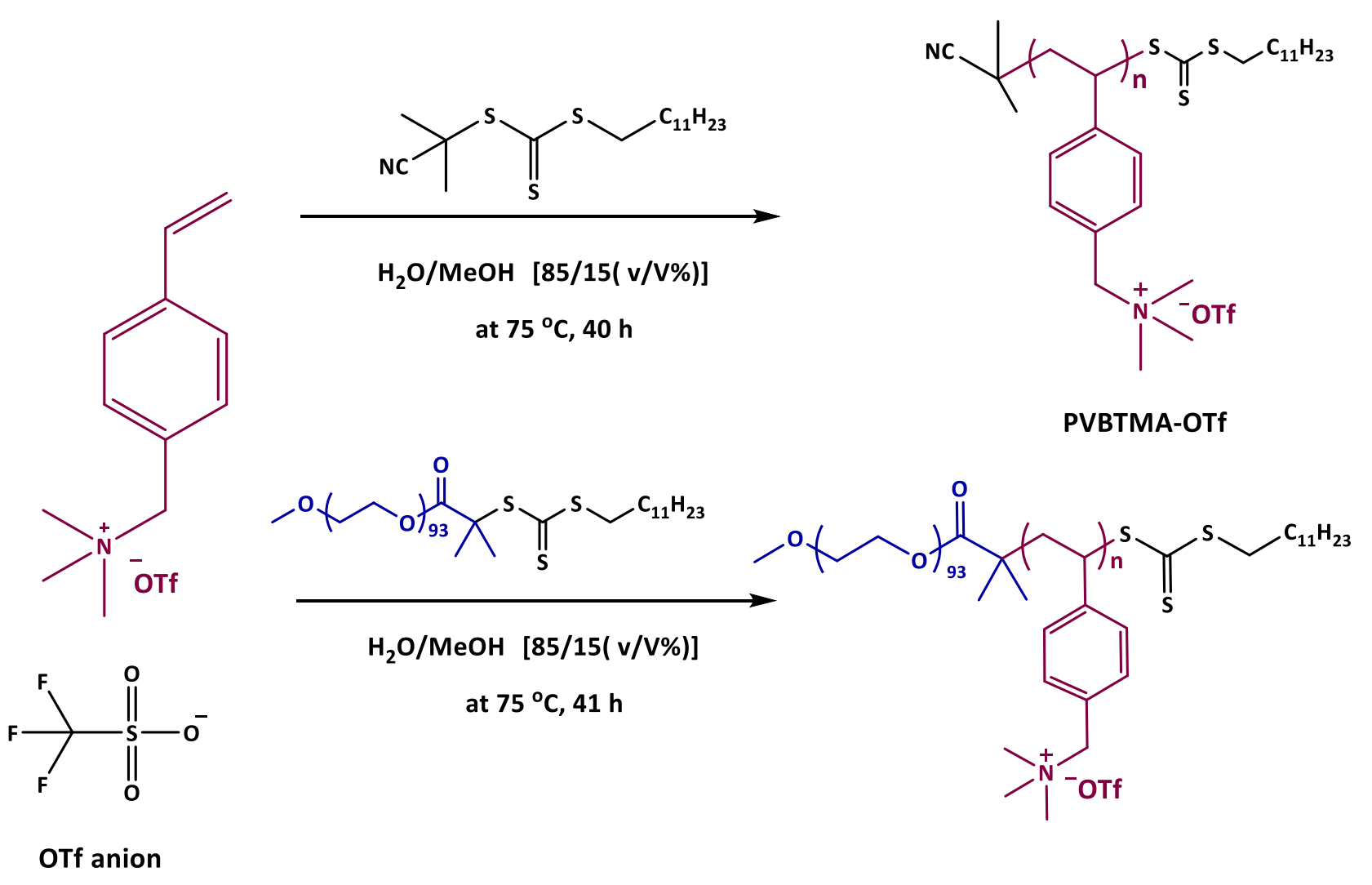

PEG-PVBTMA-OTf

Scheme1. Synthesis of homo and diblock copolymers of VBTMA -OTf via RAFT polymerization. 
Phase separation and mixing of the polymers in aqueous LiOTf solutions

The homopolymer PVBTMA-OTf and the diblock copolymer PEG-PVBTMA-OTf are both soluble in pure water and do not show any thermal transitions. However, they behave very differently in aqueous lithium triflate solutions. Whereas the homopolymer shows only UCST in aqueous LiOTf, the block copolymer goes through both a cloud $\left(T_{c U}\right)$ and a clearing point $\left(T_{c L}\right)$. Upon cooling, the aqueous block copolymer first turns turbid $\left(T_{c U}\right)$ and then, partially clarifies $\left(T_{c L}\right)$. The appearance of the $T_{c L}$ depends on the concentration of OTf anion. In the following, we shall first discuss the observations by transmittance and calorimetric measurements on the homopolymer and after this, we show the corresponding findings for the block copolymer. The cloud point temperatures $T_{c u}$ and $\mathrm{T}_{\mathrm{CL}}$ were determined from the normalized transmittance curves as shown in Figure S3.

\section{Homopolymer PVBTMA-OTf. Transmittance and DSC}

The homopolymer PVBTMA-OTf is soluble in pure water at room temperature but upon the addition of LiOTf the transparent polycation solution turns opaque. This was observed already during the synthesis in a water/methanol mixture where the initially clear reaction mixture turned cloudy when cooled down to room temperature.

Firstly, the effect of LiOTf on the solutions was studied. The UCST type phase separation appeared at room temperature already at $10 \mathrm{mM}$ of LIOTf in the $1 \mathrm{mg} \mathrm{mL}^{-1}$ aqueous polymer. $10 \mathrm{mM}$ is in this case a notable concentration compared to that brought to the solution as the counterion in the polymer $(3 \mathrm{mM})$. When the salt concentration was increased to $100 \mathrm{mM}$ the UCST phase transition disappeared, i.e. the polymer was insoluble. It was observed that stable dispersions form only when the LiOTf concentration is in the range $20-30 \mathrm{mM}$. With higher amounts of salt the polymer slowly precipitates at room temperature. 
The instability of the formed polymer particles at higher LiOTf concentrations is explainable with competition between dissociation and ion pairing at the surface of the formed associate. With lower concentrations, the charged groups near the surface will dissociate and positively charged particles will form. This leads to colloidally stable particles. If a significant amount of OTf counter ions is already present in the solution, dissociation becomes less favorable and more OTf ions will be bound to the particle surface, which leads to the precipitation of the polymer. A similar interplay between ion pairing and dissociation is probably also behind the fact that a threshold concentration of LiOTf is needed before the polymer becomes insoluble in water, although there is already a stoichiometric amount of OTf ions compared to the cationic repeating units.

Next, the influence of the polymer concentration on the phase separation in aqueous solutions with constant salt concentration $(30 \mathrm{mM})$ was studied. The transmittances of the solutions were measured while first cooling and then heating the samples. The data and the corresponding phase diagram are shown in Figure 1. Note that we take the upper inflection point as the cloud point $T_{c u}$, consult Figure $S 3$. $T_{c u}$ is not only dependent on the added LiOTf but also strongly depends on the polymer concentration. There was a 10 minutes interval between the cooling and heating cycles and correspondingly, the transmittance values at $35^{\circ} \mathrm{C}$ are different. From the phase diagram we see that $T_{c u}$ reaches the maximum at $0.5 \mathrm{mg} \mathrm{mL}^{-1}$ and then decreases with further increasing the polymer concentration. This is in good agreement with the observations by Yoshimitsu et al. on the UCST of polycations $s^{8,12}$. The intra and inter molecular ionic interactions through the ion bridging cause the UCST transition or soluble-to-insoluble (S-I) phase transition upon cooling. 

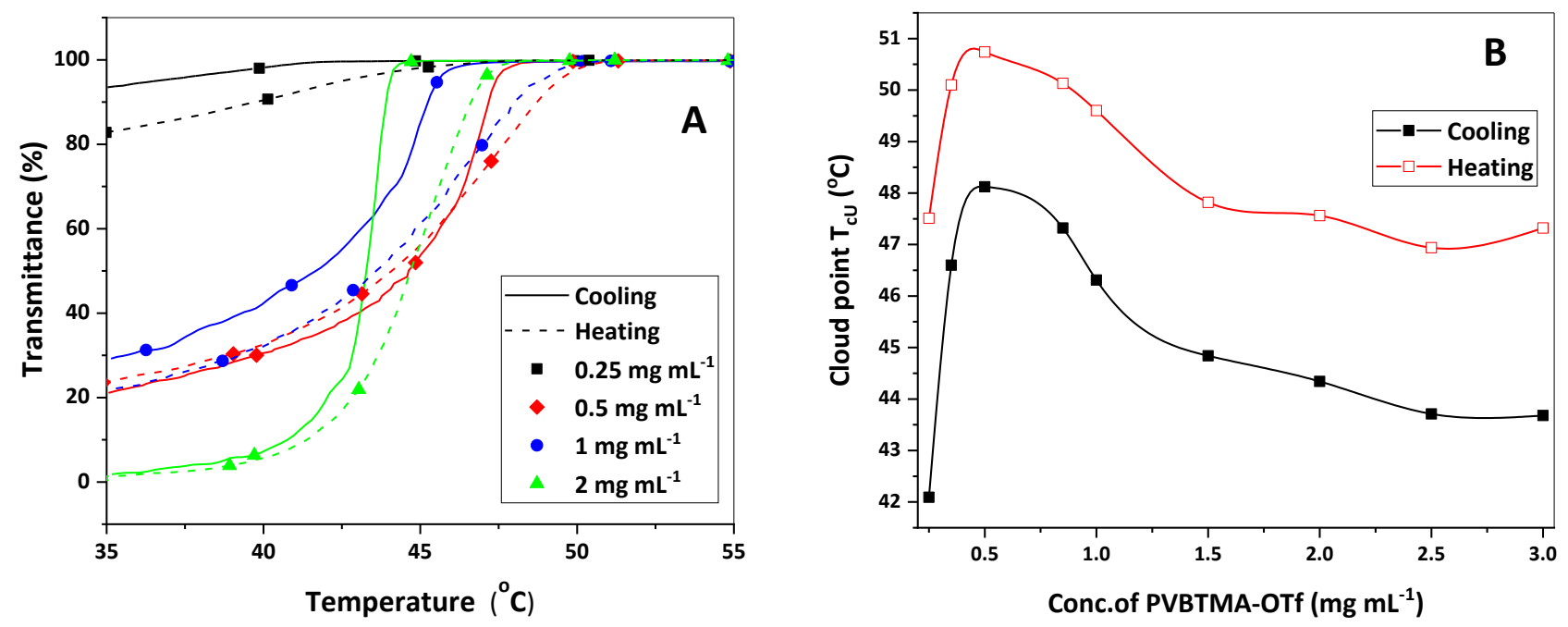

Figure 1. Data collected upon cooling and heating the samples. (A) Transmittance curves for PVBTMA-OTf solutions with various polymer concentrations and constant LiOTf concentration (30mM); and (B) Corresponding phase diagrams for PVBTMA-OTf.

Reversible phase transitions, insoluble-to-soluble (I-S transition) were observed during heating cycles with certain hysteresis $\left(\sim 5^{\circ} \mathrm{C}\right)$ for all studied polymer concentrations. The hysteresis is mainly due to the strong intra and interpolymer ionic interactions which need higher energy to break down. ${ }^{12}$ The hydrophobic end group of the polymer chain may also influence the cloud point temperature and the hysteresis, especially while increasing the temperature. The cloud points were in general not affected by changing the cooling and heating rates, however, a small change was observed in the $1 \mathrm{mg} \mathrm{mL}^{-1}$ PVBTMA-OTf solution in the presence of $30 \mathrm{mM}$ LiOtf, see Figure S4.

The phase separation can well be observed with micro calorimetry, especially during cooling the samples. The onset points of the thermograms in Figure 2 are shown in Figure 3 and they correspond to the transmittance data. The transitions observed during cooling runs are much sharper than those measured during heating. The phase separation and mixing processes are most conveniently followed during the cooling of the samples because while doing this we start from homogeneous solutions. The absolute values of the enthalpy changes are 
close to each others. The enthalpies are shown and discussed further below (in Figure 6) together with the values from the block copolymers.
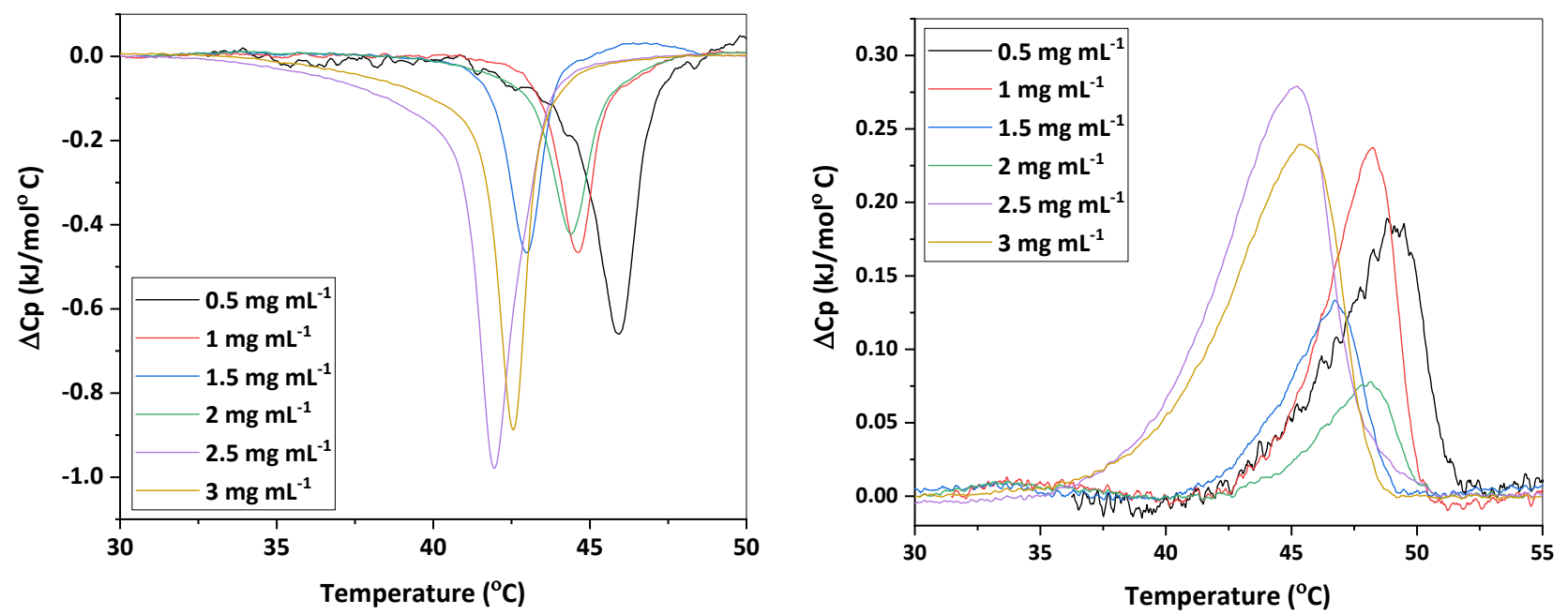

Figure 2. The micro-DSC thermograms for PVBTMA-OTf different polymer concentration solutions with constant LiOTf (30 mM). Cooling on the left, heating on the right.

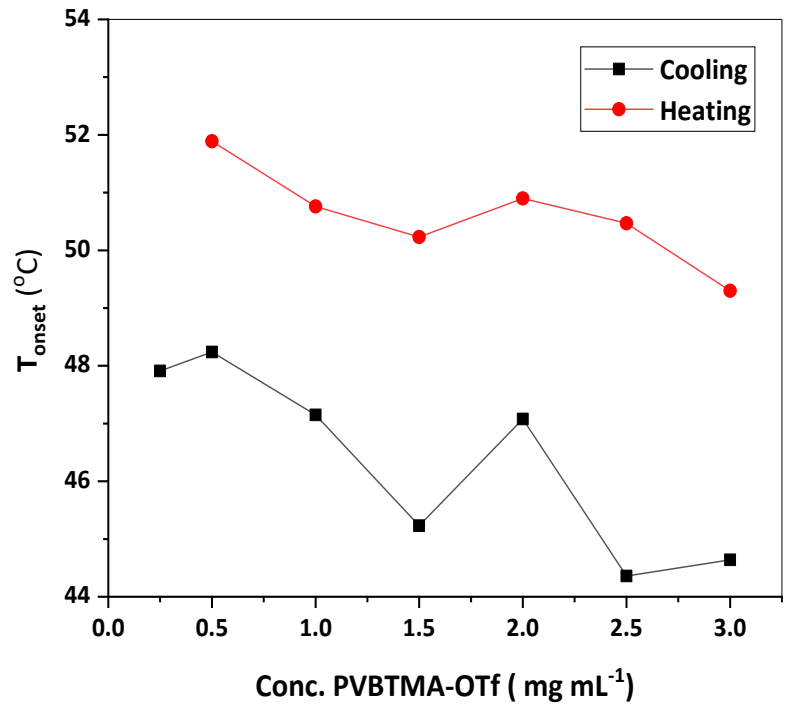

Figure 3. Onset temperatures from the thermograms in Figure 2. 


\section{Diblock copolymer PEG-PVBTMA-OTf. Transmittance and DSC}

The block copolymer dissolves in pure water at room temperature and a clear solution is obtained, but adding of LiOTf induces cloudiness. Figure 4 shows the transmittance of PEG-PVBTMA-OTf solutions with a constant polymer concentration $(1 \mathrm{mg} / \mathrm{mL})$ and varying salt concentration upon cooling, and the phase diagrams from both cooling and heating cycles. The $T_{c L}$ data, however, could not be collected from the heating curves. The transmittance curves measured with heating can be found in the Supporting Information (S5). As in the case of the homopolymer the phase separation processes are observable within a certain salt concentration range.

As is seen in Figure 4A, when the salt concentration is above $50 \mathrm{mM}$, two consecutive transitions appear. When cooling the samples from $55{ }^{\circ} \mathrm{C}$, they suddenly turn turbid and but partially clarify upon further cooling. An important observation is that the $T_{c L}$ disappears when the salt concentration exceeds $100 \mathrm{mM}$.
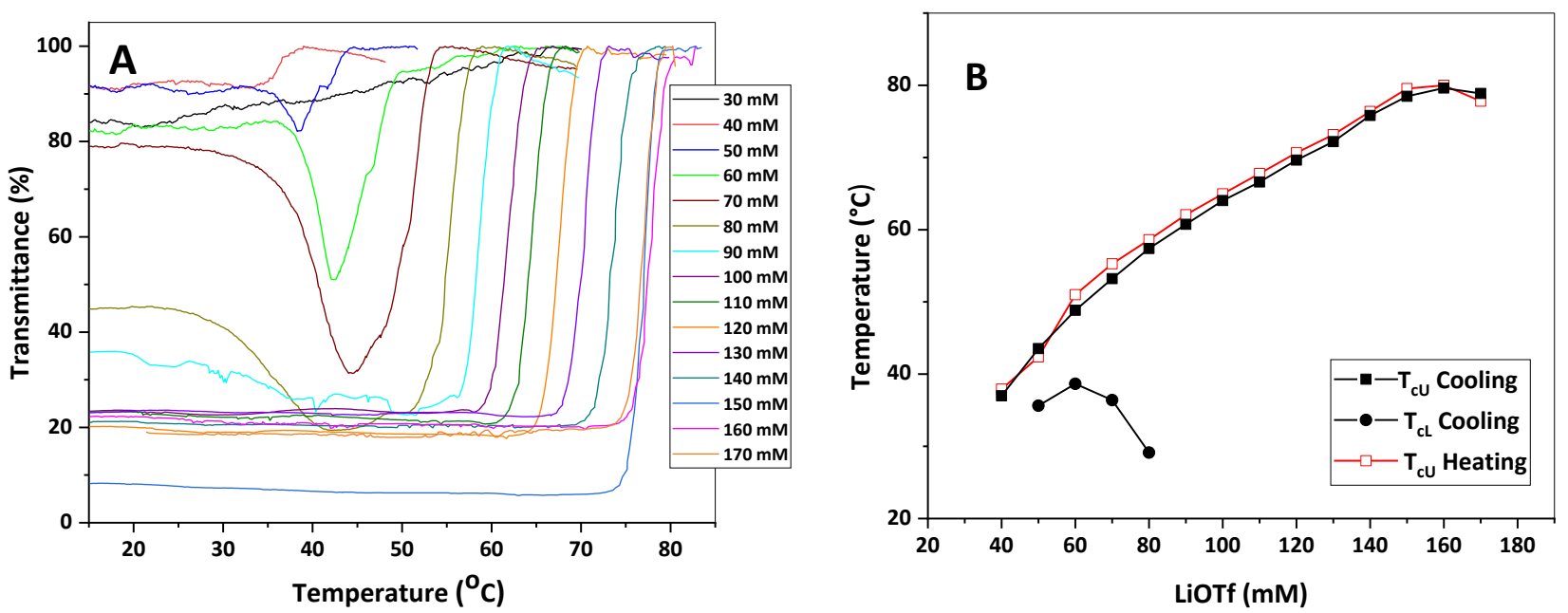

Figure 4. (A) Transmittance curves measured during cooling for PEG-PVBTMA-OTf $(1 \mathrm{mg} / \mathrm{mL})$ with LiOTf concentrations from 30 to $170 \mathrm{mM}$ and (B) Phase diagrams for PEG- PVBTMA-OTf cloud point temperatures $T_{\mathrm{cL}}$ and $T_{c u}$ as a function of salt concentration upon both cooling and heating. 
Thermal behavior of PEG-PVBTMA-OTf solutions is very strongly dependent on the ratio of cations to anions. Series of transmittance curves of polymer solutions with constant LiOTf concentration but varying polymer concentration is shown in Figure 5, together with a phase diagram. Knowing the correlation between the overlap concentration, the molar mass and the radius of the polymer it is clear that the studied solutions are in the dilute regime. Interestingly we see that the phase separation at the $T_{c u}$ takes place in two steps, the first one observed as a shoulder in the transmittance curve at high polymer concentrations and as a separate peak with low polymer concentrations. The cloud points are collected in a phase diagram in Figure 5B. The $T_{c u}$ increases with polymer concentration up to a certain limit, around $2 \mathrm{mg} / \mathrm{mL}$ (cation to anion ratio approximately 1:10) and keeps constant above this. The finding is important and suggests that the ratio describes the approximate number of counterions clouding around the polymer, and especially around the cationic repeating units. Chaotropic anions as OTf are known to interact with ethyleneoxide units and to group around tertiary amines. ${ }^{23,27}$ The interactions between the polymer repeating units, water, and ions is schematically shown in Scheme 2.
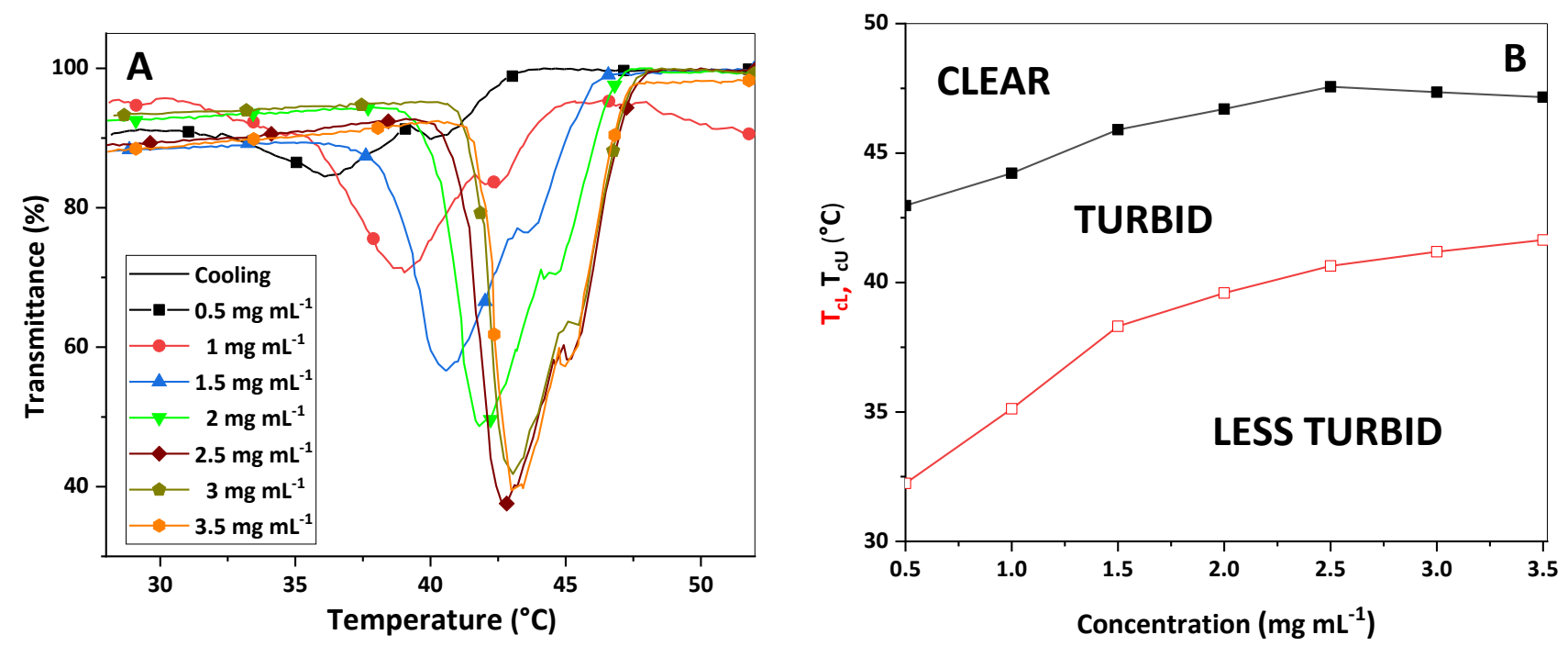

Figure 5. (A) Transmittance curves of polymer solutions with constant LiOTf concentration (50 Mm) and varying polymer concentration and (B) the corresponding phase diagram. 

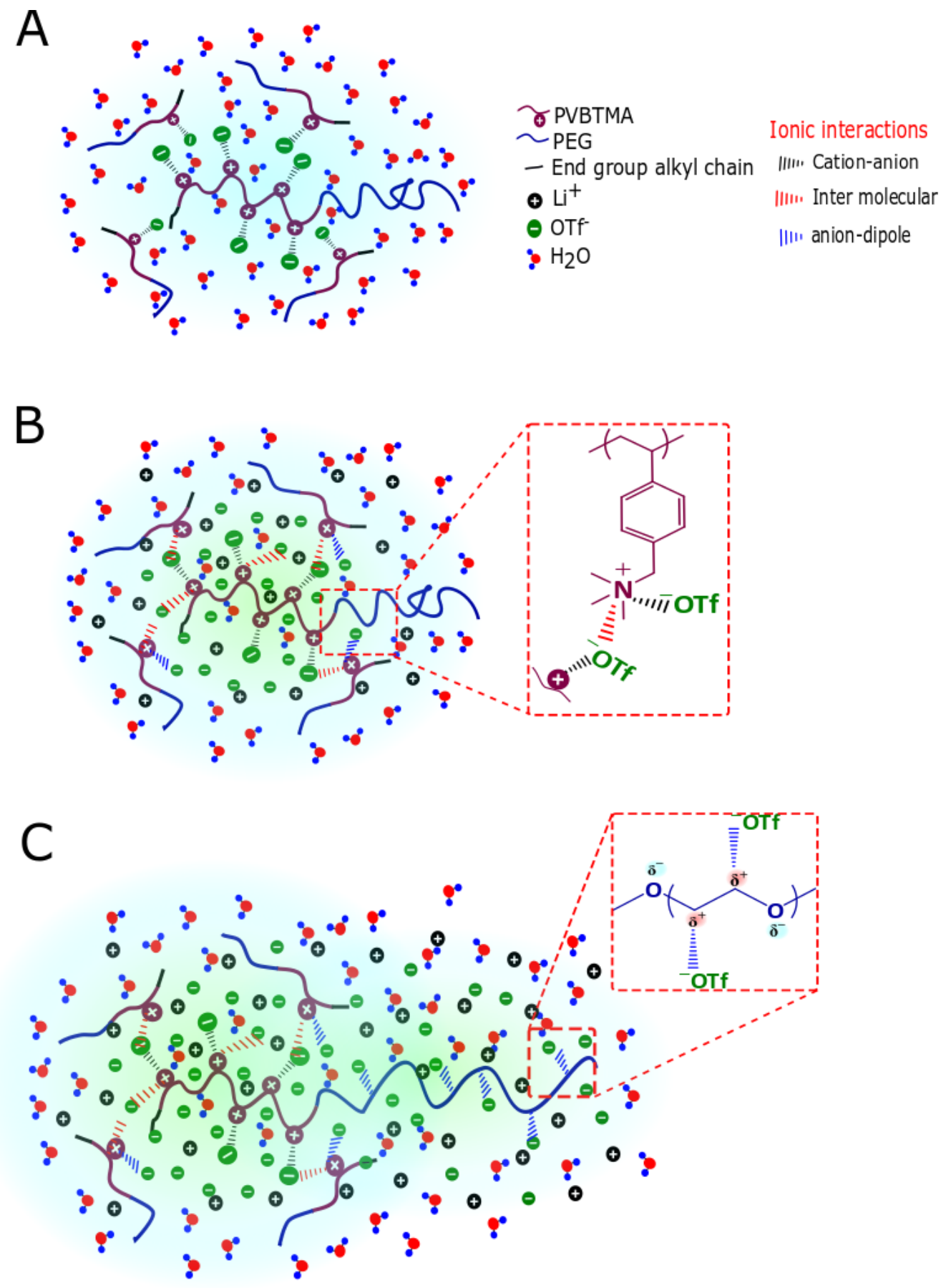

Scheme 2. Illustration of the counterion - polymer interactions in $(A)$ in pure water, no thermal transitions; (B) in $40 \mathrm{mM}$ LiOTf, UCST observed; (C) in $50 \mathrm{mM}$ LiOTf, two transitions. 
Figure 6 presents the thermograms of PEG-PVBTMA-OTf with varying polymer concentration and a fixed salt concentration $(50 \mathrm{mM})$. In this case the onset of the transition in the cooling scans is more instantaneous than in the case of homopolymer. The transition is broad and step-wise, as was observed in the transmittance studies.

Enthalpy changes of the phase transitions of both the homopolymer and the block copolymer measured through cooling and heating scans are shown in Figure 7. In spite of the observed thermal hysteresis the functions are symmetrical, indicating that even though in some cases the absolute values measured during cooling are higher than the corresponding values measured in the heating runs, overall the transitions are reversible in the time scale of the measurement. That the transitions observed as varying degrees of cloudiness are associated with enthalpy changes indicates that the processes, which occur during cooling the solution, are not just morphological changes in the aggregates.
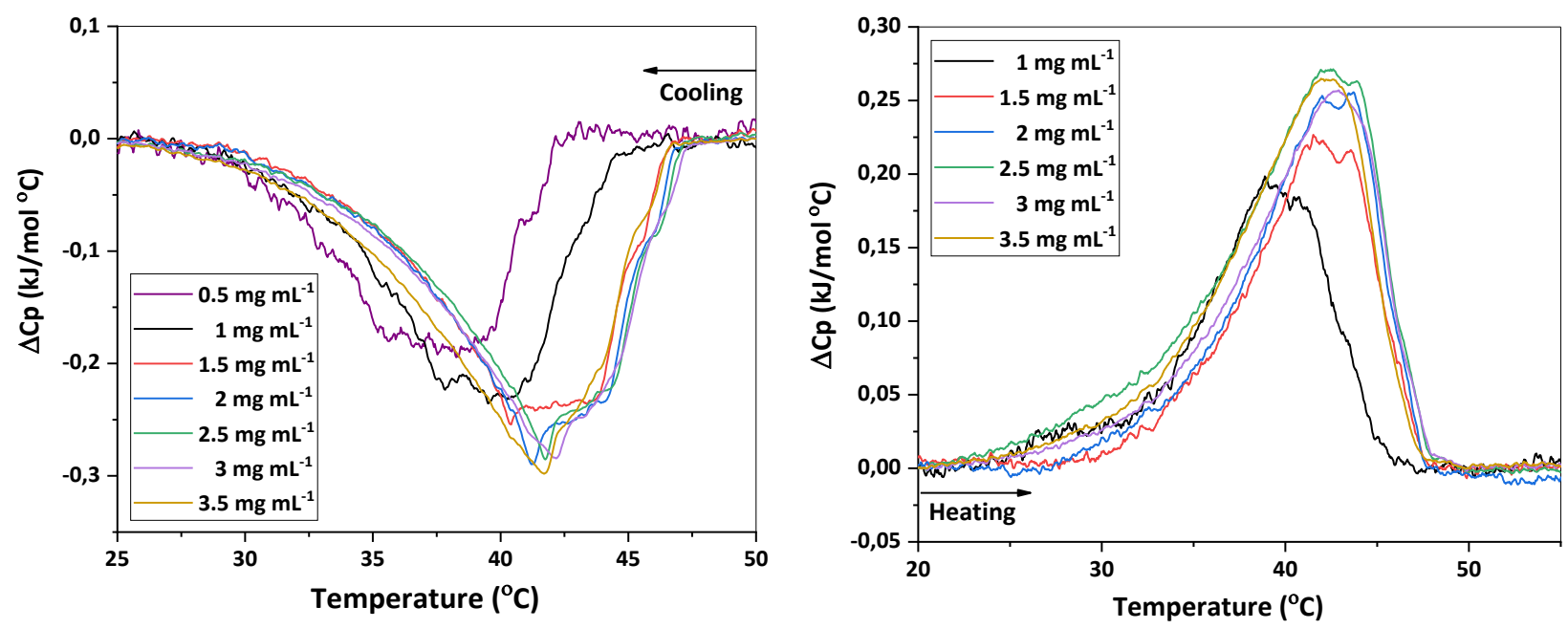

Figure 6. The micro-DSC thermograms for PEG-PVBTMA-OTf different polymer concentration solutions with constant LiOTf salt heating (right) and cooling (left). 


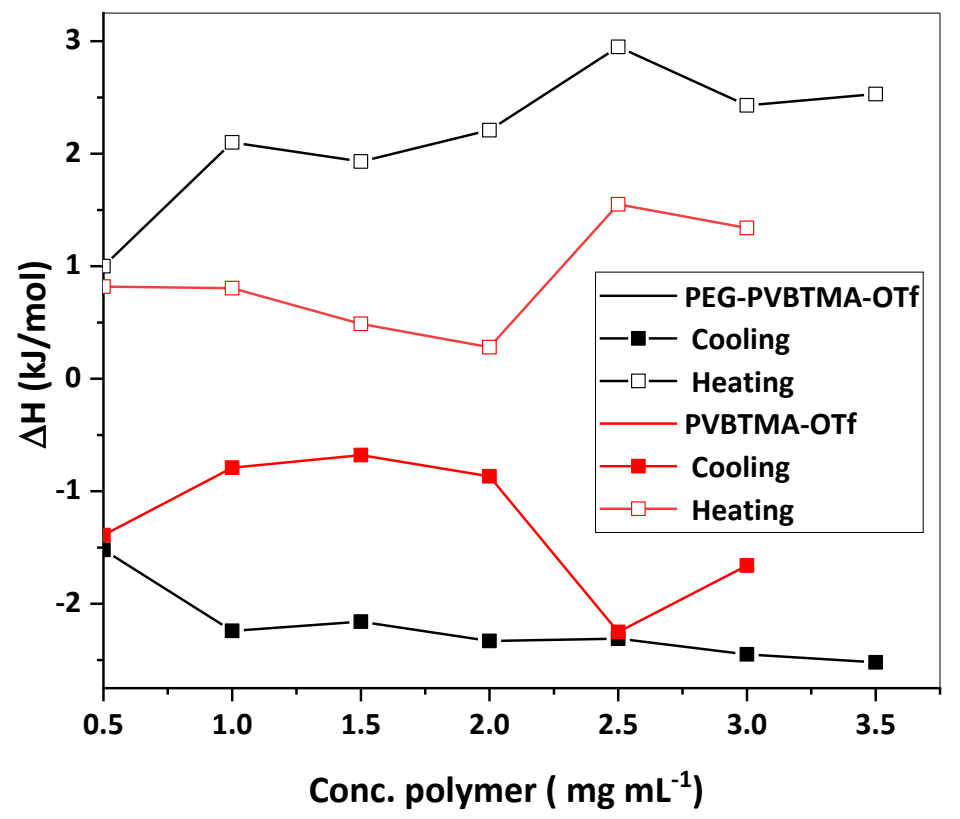

Figure 7. Transition enthalpies measured for the homopolymer (red) and the block copolymer (black) during cooling (first) and heating (second) scans. The $\Delta \mathrm{H}$ is given as $\mathrm{kJ}$ per repeating cationic monomer unit.

The fact that the homopolymer in aqueous LiOTf shows only UCST behavior but the block copolymer under similar conditions goes through a cloud point and a clearing point while being cooled, deserves to be further discussed. The phase transition behavior of the diblock copolymer is, in fact, even more complicated. In Figure 5 one can see how upon cooling the system, the turbidity increases in steps. Whether the first step is observed as a shoulder or a separate peak depends on the polymer concentration.

The stepwise clouding and partial clearing may be understood based on the observation that PEG-PVBTMA-OTf is not soluble in aqueous triflate at room temperature but forms micelles/vesicles. Evidently the micelles/vesicles are stabilized by PEG chains dangling in the aqueous triflate solution. Increasing thermal energy loosens the bridging between PEG and the triflate ions. ${ }^{33}$ The increase of turbidity in the temperature range $35-45{ }^{\circ} \mathrm{C}$ is then obviously due to the aggregation of the micelles which is accompanied by the binding of the PEG chains to the surfaces of the positively charged particles, directly or through ionic bridging ${ }^{27,33,34}$. At higher temperatures 
(around $50{ }^{\circ} \mathrm{C}$ ) the polycation turns soluble and the micelles/vesicles disintegrate. Thus, we conclude that the driving force for the step wise phase separation of the diblock copolymer is the interaction of the cationic block and the PEG block, mediated by counter ions. The interaction of chemically different blocks is not, however, spontaneous. When two homopolymers, PVBTMA-OTf and PEG macroCTA are dissolved in aqueous LiOTf in the same ratio as in the experiments above, only one process is observed at the UCST of the PVBTMA-OTf. The transmittance curve for a mixture of PEG macroCTA and PVBTMA-OTf is shown in Supporting Information, Figure S7. It needs to be noted that the PEG macro CTA phase separates at temperatures above $90^{\circ} \mathrm{C}$ in the presence of $50 \mathrm{mM}$ LiOTf.

The short hydrophobic block in the end of the polycation may further complicate the phase separation process, as well as the fact that the aqueous phase contains triflate anions which are considered as chaotropic ones. These points will be discussed further below.

Some more experiments were conducted measuring the transmittances of polymer mixtures. This was considered necessary because after the synthesis we failed to separate the possible homopolymer PVBTMA-OTf from the block copolymer. Also, a possibility exists that unreacted macroCTA may be left in the sample in spite of careful dialysis. Thus, samples were prepared where into the block copolymer, 20 mass\% of homopolymer or 18 mass\% of PEG were added. The transmittance curves are shown in Supporting Information, Figure S7. The experiments proved that even the high quantities of added polymers did not change the main observation, that the homopolymer shows the UCST and the block copolymer both $T_{c U}$ and $T_{c L}$. The fact that the addition of homopolymer to the solution of the block copolymer supresses the $T_{C L}$ transition may be rationalized by assuming that the ratio of the number of the cationic repeating units to that of the free (dissociated) triflate ions is an essential parameter. As already noted, the chaotropic triflate ions prefer binding to the cations ${ }^{35}$ and adding an extra amount of the polycation consumes a number of free triflates. Thus, the PEG block behaves as it would in 
a less saline solution. Intersting questions for further studies are the comparison of various counterions (chaotropic vs. kosmotropic), the effects of the length of the polycation block, and that of the hydrophobic end group.

\section{Light scattering on the solutions of PEG-PVBTMA-OTf}

The phase separation and partial remixing can be observed visually, as is shown in photographs in Figure 8 . The same sample was measured by light scattering, and the intensity averaged size distributions at three temperatures are also added in Figure 8. The intensity averaged function at high temperature is bimodal owing to the polyelectrolyte effects, and the corresponding volume averaged distribution is shown as well.
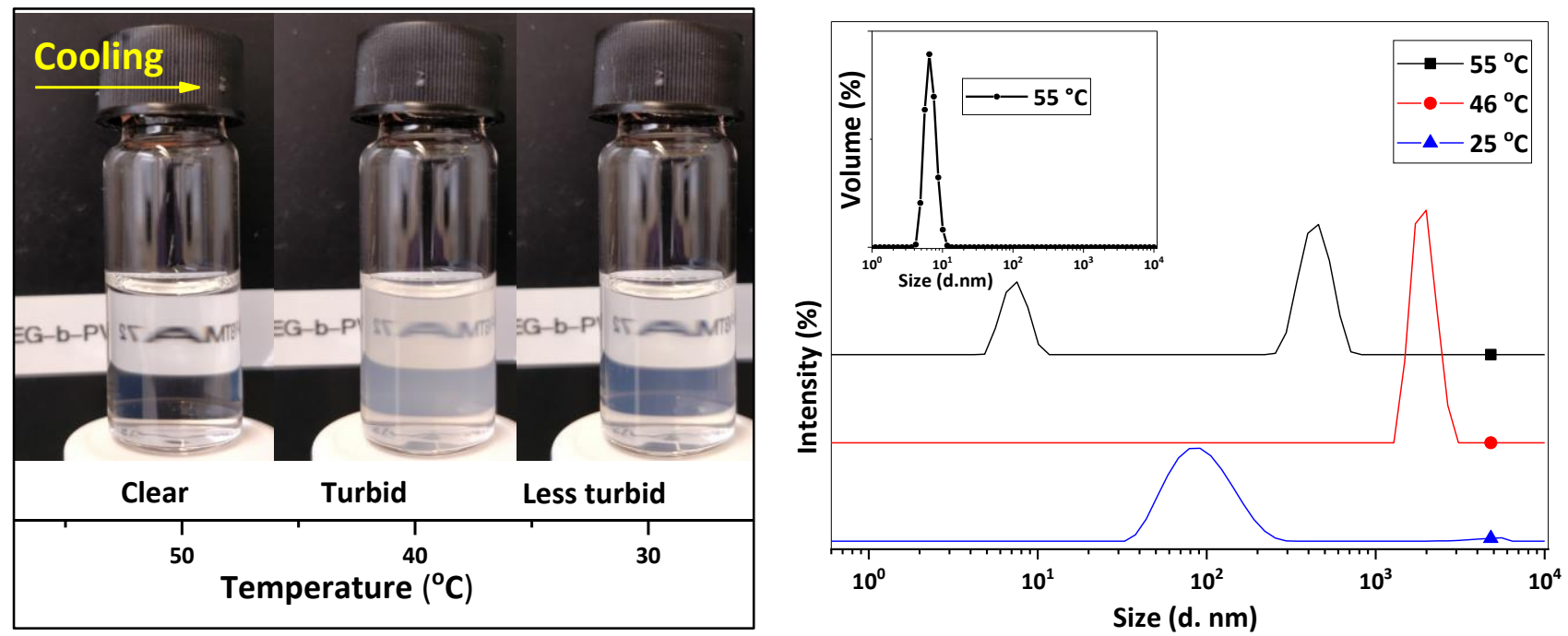

Figure 8. Left: Photographs of the sample at three temperatures, right: size distributions measured at $173^{\circ}$ scattering angle of PEG-PVBTMA-OTf. $2 \mathrm{mg} \mathrm{mL}^{-1}$ polymer in $50 \mathrm{mM}$ LiOTf solution. Symbols! Insert the volume average!

Intensity of scattered light is weak for PEG-PVBTMA-OTf ( $2 \mathrm{mg} \mathrm{mL}^{-1}$ in $50 \mathrm{mM}$ LiOTf solution) above $50{ }^{\circ} \mathrm{C}$ owing to thermodynamically good quality of solutions, see Figure S8. Weak scattering makes detailed multi angular DLS analysis difficult. However, DLS was studied using back scattering angle ( $\theta=173^{\circ}$, ZetaSizer), which gives a large scattering volume. The selected results are shown in Figure 8 . At $55^{\circ} \mathrm{C}$ the polymer is molecularly dissolved and 
the dimension of the polymer is of the order of $10 \mathrm{~nm}$. Figure $\mathrm{S} 8$ reveals clear peaks in LS intensity as a function of temperature between 42 and $50^{\circ} \mathrm{C}$. Positions of the peaks upon step wise cooling down from 70 to $20^{\circ} \mathrm{C}$ followed by heating remain the same though the area under the peak obtained upon heating is significantly smaller. This is in line with microcalorimetric studies (Figure 6) and suggests thermal hysteresis: the rate of the polymer redissolution is slower and more time is required for the chain expansion. ${ }^{2,36}$ In the case of PEGPVBTMA-OTf ( $2 \mathrm{mg} \mathrm{mL}^{-1}$ in $50 \mathrm{mM}$ LiOTf solution) we observe two transitions (see Figures 5 and 6 ), the rates of which may differ and result in hysteresis. LS intensity increases upon further cooling below $42{ }^{\circ} \mathrm{C}$ due to worsening of the solvent quality. Below $42^{\circ} \mathrm{C}$ and above $50{ }^{\circ} \mathrm{C}$, LS intensity is the same upon cooling or heating thus suggesting reversible process.

While comparing the DLS data collected at 25,45 , and $55^{\circ} \mathrm{C}$ the main observations are the following. At the highest temperature the polymer is dissolved and in a coiled conformation, and the scattering intensity is low. Small number of large multimolecular aggregates may be present in solution. Between 42 and $50^{\circ} \mathrm{C}$, LS intensity is too high due to the formation of large multimolecular aggregates, multiple scattering does not permit analysis on the radius of gyration $\left(\mathrm{R}_{\mathrm{g}}\right)$. When the liquid is cooled to $45^{\circ} \mathrm{C}$ (the "turbid region" in the phase diagram, see Figure 5) we observe homogeneously sized but huge scattering objects (diameter over $1000 \mathrm{~nm}$ at $\theta=173^{\circ}$ ). At $25^{\circ} \mathrm{C}$ the diameter of the scatterers is of the order of $100 \mathrm{~nm}$ and the $R_{g} / R_{h}$ ratio is of the order of 1.0 , obviously indicating the presence of drain-through structured entities. To conclude, the polymer aggregates existing at room temperature coagulate to large but loose ensembles at $45^{\circ} \mathrm{C}$, but totally disintegrate upon further heating.

The multi-step phase separation and mixing processes were demonstrated also in an experiment where scattered light intensity was followed with continuously changing temperature (approximately $1^{\circ} \mathrm{C} / \mathrm{min}$ ). First, the sample was allowed to cool from 55 to $25^{\circ} \mathrm{C}$ and after 3 minutes, it was reheated. Measuring the exact temperatures during this exercise was not possible but the result (Figure 9) shows how in a cooling liquid, huge scattering objects appear and then vanish. For a while, they reappear when again heating the system. An overall description of the macromolecular self-assemblies is given in Scheme 3. 


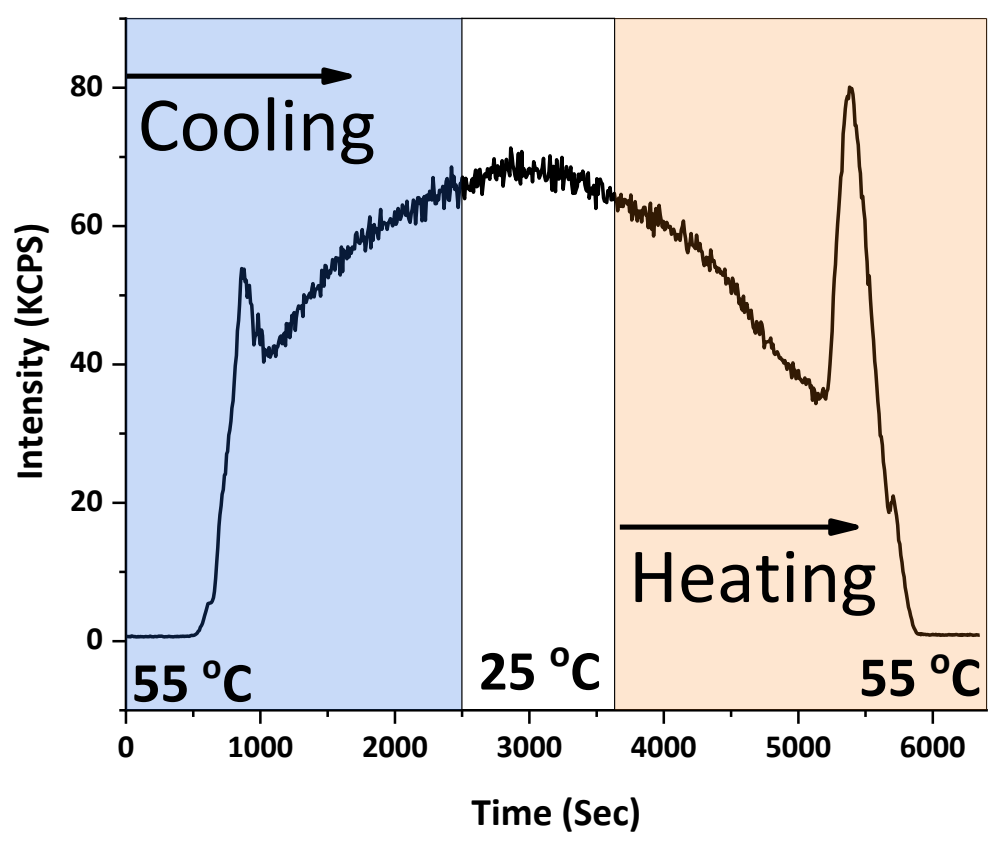

Figure 9. The scattered light intensity of PEG-PVBTMA-OTf solution ( $2 \mathrm{mg} \mathrm{mL}^{-1}, 50 \mathrm{mM}$ of Li OTf) upon cooling and heating cycle. 


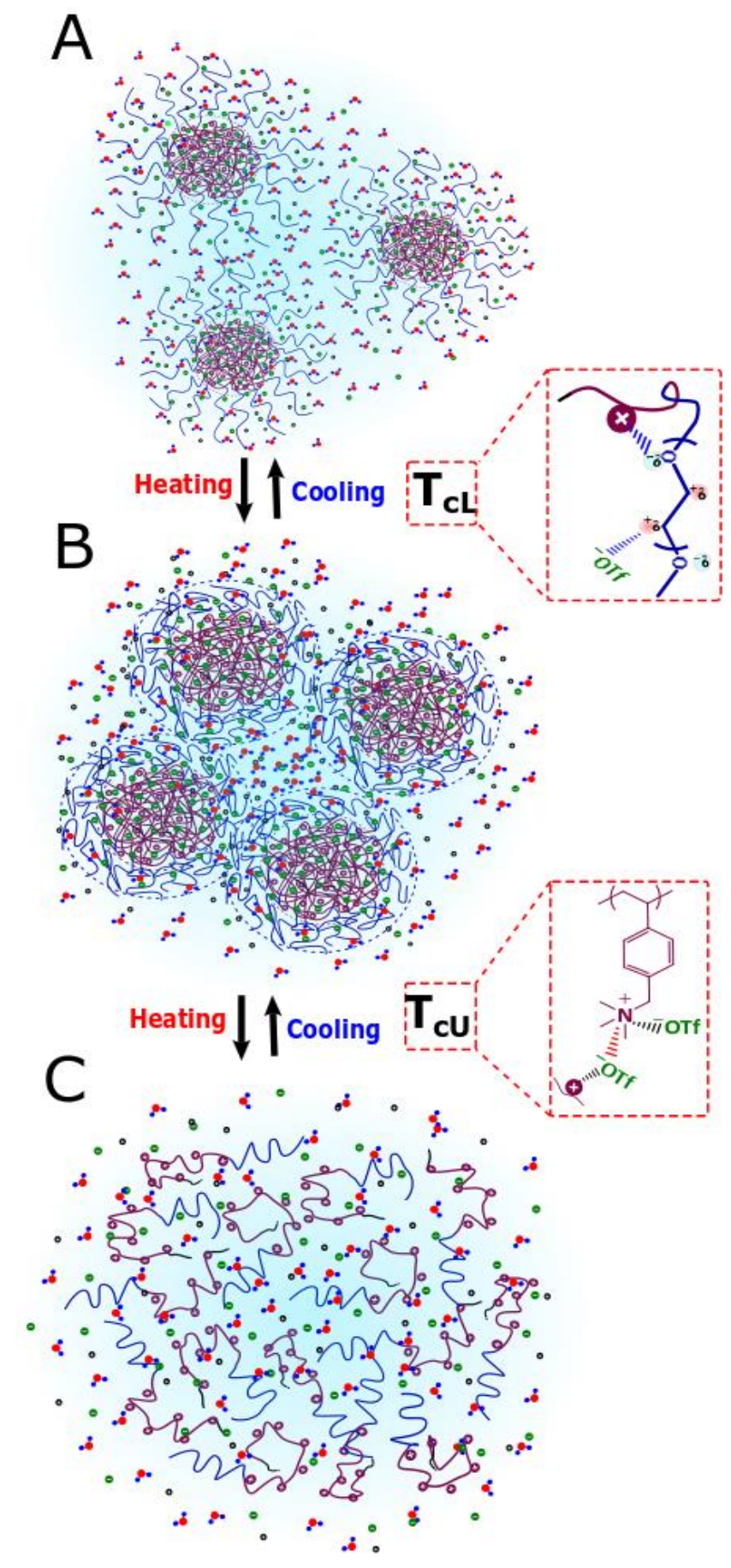

Scheme 3. Polymer assemblies in $50 \mathrm{mM}$ LiOTf at different temperatures. (A) Less turbid dispersion at $25^{\circ} \mathrm{C}$; spheres with PEG coronas, (B) turbid dispersion at $45^{\circ} \mathrm{C}$; aggregates of spheres, (C) solution at $55^{\circ} \mathrm{C}$. 


\section{NMR studies on solutions of PEG--PVBTMA-OTf}

Parts of the ${ }^{1} \mathrm{H}$ NMR spectra of a $2 \mathrm{mg} / \mathrm{ml}$ solution of PEG-PVBTMA-OTf in $50 \mathrm{mM}$ LiOtf at various temperatures are shown in Figure 9. The spectra were recorded during cooling the samples. The integrated intensities of the signals from the polycation backbone, the aromatic ring, and the quaternary ammonium change discontinuously during the phase separation of the polymer (Figure 10), as was expected. The data indicates the build-up of a cationic core in a core-shell structure. ${ }^{37}$ The shape but not the intensity of the signal of PEG changes with temperature. At temperatures below $30^{\circ} \mathrm{C}$ the signal is clearly a superposition of a narrow and a broad resonance line. At higher temperatures, mainly the narrow line can be detected. This indicates that in the aggregates observed at $25{ }^{\circ} \mathrm{C}$, part of the PEG chains are bound to the aggregated polycation. Spěváček et al. ${ }^{38,39}$ have extensively studied the phase separation of block copolymers of PEO and PNIPAm and shown that the integrated intensity of PEG decreases at elevated temperatures where the PNIPAm block has collapsed. The behavior of the present polymer is not perfectly analogous even though the interactions at low temperatures are visible. Similar motional freedom of the PEG blocks was observed by NMR also in the case of PEG-polyzwitterion block copolymers. ${ }^{27}$ The appearance and disappearance of the large particles between $T_{c U}$ and $T_{c L}$ occurs in a very narrow temperature range and could not be detected.

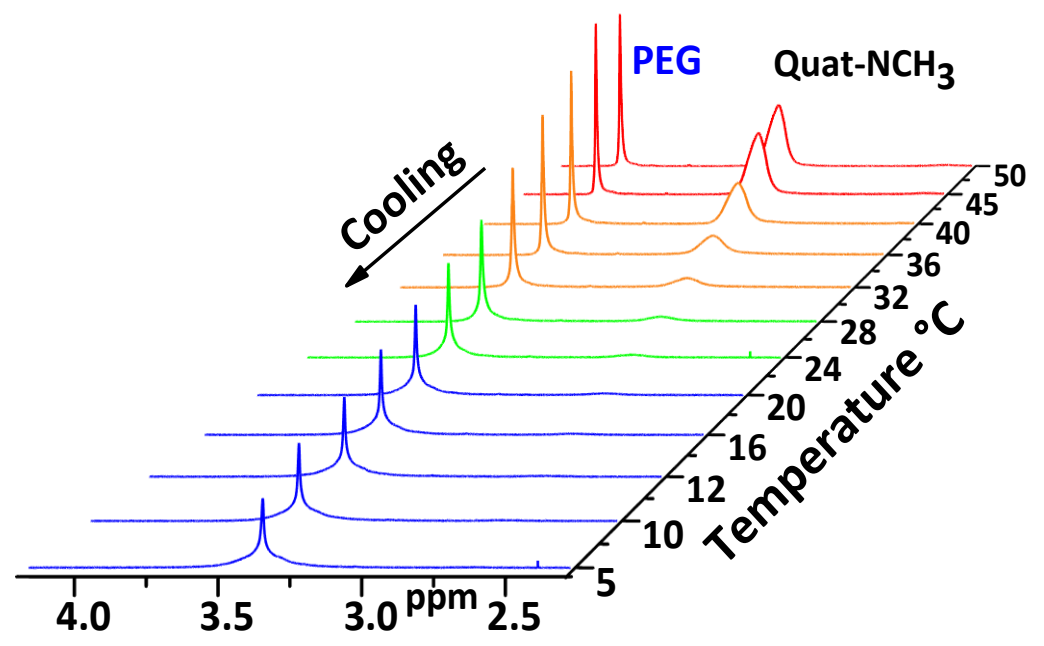


Figure 10. ${ }^{1} \mathrm{H}$ NMR spectral lines of PEG and the protons of the quaternary ammonium in PEG-PVBTMA-OTf with $2 \mathrm{mg} \mathrm{mL}^{-1}$ polymer concentration in $50 \mathrm{mM}$ LiOtf solution as function of temperature.

The NMR measurements were conducted twice. After the first series of measurements, the polymer was dialysed against water for a week, freeze-dried, and redissolved in aqueous triflate. This convinced us of the evident fact the narrow PEG signal is not from an impurity but from the PEG block of the copolymer. The finding is important and shows that within the whole temperature range being studied there are, more or less, freely tumbling PEO chains which contribute to the colloidal stability of the polymer particles. As one can see in Figure 11 the integrated intensity of the PEG signal is constant through the measured temperature range.

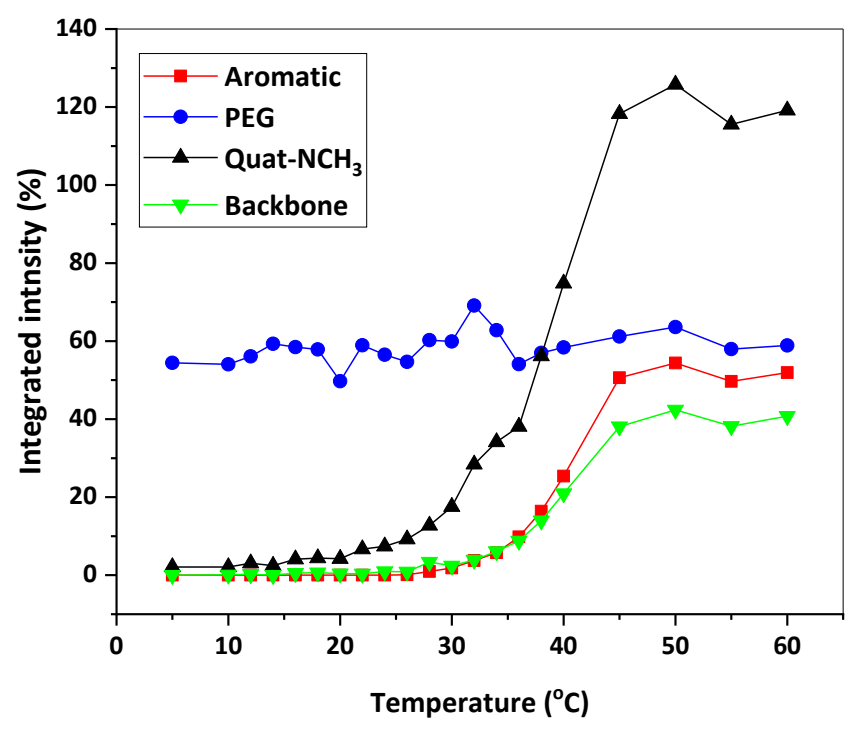

Figure 11. Integrated intensities of the NMR signals against temperature, sodium formate was used as a reference. Corresponding data without the added formate is shown in Supporting Information, Figure S9. In this latter case, water signal was used as a reference. 


\section{Conclusions}

Cationic block copolymer PEG-PVBTMA-OTf has been synthesized through RAFT polymerization in a water/methanol mixture using a PEG macro chain transfer agent. Solution properties of the block copolymer have been compared to those of the homopolymer PVBTMA-OTf. Both the block copolymer and the homopolymer carry triflate anions as counter ions.

The behavior of the aqueous polymers is strongly dependent on the addition of salt, LiOTf in this case. In the presence of salt, the homopolymer undergoes a rapid dissolution process at the critical temperature $T_{c U}$ (UCST). $\mathrm{T}_{c U}$ is dependent on the salt and the polymer concentrations.

When cooling the solutions of the block copolymer the polymer undergoes consecutively a soluble-insoluble transition at the $T_{c u}$ and an insoluble-soluble transition at the $T_{c L}$. It has been shown that the two transitions are because of the two mutually interacting blocks when the blocks are covalently connected to each other. The S-I transition observed upon cooling is step wise, and such is the corresponding I-S transition observed with heating. This is indicative of several inter and intramolecular interactions in play during the phase separation and phase mixing.

Based on the experimental data collected in this work it is possible to rationalize the thermal processes by taking into account the existence of ionic interactions, the interactions between the cationic groups and ether oxygens, as well as hydrophobic interactions between the short hydrophobic stickers in the chain ends. OTf anions serve as hydrophobic counter ions without which the UCST of the polycation would not be observed at all. There is evidence that triflate ions are chaotropic ones which can bind even to nonpolar hosts. ${ }^{40}$ So far we do not know more about the chaotropicity of the ions but their role in mediating the ionic interactions seems clear. The occurrence of the $T_{C L}$ is because the two different polymers are covalently bound to each other, and because the triflate ions facilitate their interaction. 
The overall picture of thermal behavior of the block copolymer is the following. At high temperature, around 55 ${ }^{\circ} \mathrm{C}$, the polymer dissolves more or less molecularly. The hydrophobic interactions between the short alkyl chain ends do not disappear with temperature but they are overdriven by the dissolution of the polyelectrolyte. In the dissolved state the polymer is in a coil like conformation. Cooling the solution to the intermediate temperature range (the "turbid region" in the phase diagram) forces the polycation to collapse and aggregate (step 1 of the soluble-insoluble transition). Loose particles stabilized by PEG chains are formed but owing to the anion mediated interaction forces, large coagulates build up. During further cooling, in the step 2 of the transition, the collapse of the polycation continues. Finally, at room temperature (the "less turbid region" in the phase diagram) the polymer coagulates have disappeared owing to the total compression of the polycations into nanoparticles, stabilised by the soluble PEG blocks. PEG-PVBTMA-OTf polymer is dispersed in the aqueous medium as micelle like aggregates where the hydrophobic stickers and the ionic units are in the core.

Changes in the conformation and in the aggregation state of the PEG-PVBTMA-OTf chains in the aqueous triflate solutions turned out to be complicated. The present study shows how in detail one may modulate thermal behavior of the polymer by the choice of the counter ion and by varying the salt and polymer concentrations.

\section{Supporting information}

Syntheses, ${ }^{1} \mathrm{H}$ NMR spectra, transmittance curves, and light scattering data are presented in the Supporting Information.

\section{Author information}

\section{Corresponding Author}

*E-mail heikki.tenhu@helsinki.fi.

ORCID

Vikram Baddam:0000-0001-5327-9066 
Sami Hietala:0000-0003-1448-1813

Heikki Tenhu:0000-0001-5957-4541

\section{Acknowledgement}

VB thanks Magnus Ehrnrooth Foundation and CIMO for the research grants.

\section{References}

(1) Halperin, A.; Kröger, M.; Winnik, F. M. Poly(N-Isopropylacrylamide) Phase Diagrams: Fifty Years of Research. Angew. Chemie - Int. Ed. 2015, 54 (51), 15342-15367.

(2) Aseyev, V.; Tenhu, H.; Winnik, F. M. Non-Ionic Thermoresponsive Polymers in Water; Adv.Poly.Sci. 2011, 242, 29-89.

(3) Seuring, J.; Agarwal, S. Polymers with Upper Critical Solution Temperature in Aqueous Solution. Macromol. Rapid Commun. 2012, 33 (22), 1898-1920.

(4) Niskanen, J.; Tenhu, H. How to Manipulate the Upper Critical Solution Temperature (UCST)? Polym. Chem. 2017, 8 (1), 220-232.

(5) Yang, D.; Viitasuo, M.; Pooch, F.; Tenhu, H.; Hietala, S. Poly(N -Acryloylglycinamide) Microgels as Nanocatalyst Platform. Polym. Chem. 2018, 9 (4), 517-524.

(6) Zhang, H.; Guo, S.; Fan, W.; Zhao, Y. Ultrasensitive PH-Induced Water Solubility Switch Using UCST Polymers. Macromolecules 2016, 49 (4), 1424-1433.

(7) Ben-Naim, A. Molecular Theory of Water and Aqueous Solutions. Part 1: Understanding Water; World Scientific, 2009. 
(8) Yoshimitsu, H.; Kanazawa, A.; Kanaoka, S.; Aoshima, S. Well-Defined Polymeric lonic Liquids with an Upper Critical Solution Temperature in Water. Macromolecules 2012, 45 (23), 94279434.

(9) Liu, C.; Wang, S.; Zhou, H.; Gao, C.; Zhang, W. Thermoresponsive Poly(lonic Liquid): Controllable RAFT Synthesis, Thermoresponse, and Application in Dispersion RAFT Polymerization. J. Polym. Sci. Part A Polym. Chem. 2016, 54 (7), 945-954.

(10) Men, Y.; Schlaad, H.; Yuan, J. Cationic Poly(Ionic Liquid) with Tunable Lower Critical Solution Temperature-Type Phase Transition. ACS Macro Lett. 2013, 2 (5), 456-459.

(11) Men, Y.; Schlaad, H.; Voelkel, A.; Yuan, J. Thermoresponsive Polymerized Gemini Dicationic Ionic Liquid. Polym. Chem. 2014, 5 (11), 3719-3724.

(12) Biswas, Y.; Maji, T.; Dule, M.; Mandal, T. K. Tunable Doubly Responsive UCST-Type Phosphonium Poly(Ionic Liquid): A Thermosensitive Dispersant for Carbon Nanotubes. Polym. Chem. 2016, 7 (4), 867-877.

(13) Karjalainen, E.; Aseyev, V.; Tenhu, H. Counterion-Induced UCST for Polycations. Macromolecules 2014, 47 (21), 7581-7587.

(14) Käfer, F.; Liu, F.; Stahlschmidt, U.; Jérôme, V.; Freitag, R.; Karg, M.; Agarwal, S. LCST and UCST in One: Double Thermoresponsive Behavior of Block Copolymers of Poly(Ethylene Glycol) and Poly(Acrylamide-Co-Acrylonitrile). Langmuir 2015, 31 (32), 8940-8946.

(15) Roth, P. J.; Davis, T. P.; Lowe, A. B. Comparison between the LCST and UCST Transitions of Double Thermoresponsive Diblock Copolymers: Insights into the Behavior of POEGMA in 
Alcohols. Macromolecules 2012, 45 (7), 3221-3230.

(16) Strandman, S.; Zhu, X. X. Thermo-Responsive Block Copolymers with Multiple Phase Transition Temperatures in Aqueous Solutions. Prog. Polym. Sci. 2015, 42, 154-176.

(17) Zhang, W.; Shi, L.; Wu, K.; An, Y. Thermoresponsive Micellization of Poly(Ethylene Glycol)- $b$ Poly( N -Isopropylacrylamide) in Water. Macromolecules 2005, 38 (13), 5743-5747.

(18) Maeda, Y.; Mochiduki, H.; Ikeda, I. Hydration Changes during Thermosensitive Association of a Block Copolymer Consisting of LCST and UCST Blocks. Macromol. Rapid Commun. 2004, 25 (14), 1330-1334.

(19) Bokias, G.; Staikos, G.; Iliopoulos, I. Solution Properties and Phase Behaviour of Copolymers of Acrylic Acid with N-Isopropylacrylamide: The Importance of the Intrachain Hydrogen Bonding. Polymer. 2000, 41 (20), 7399-7405.

(20) Schmaljohann, D. Thermo- and PH-Responsive Polymers in Drug Delivery. Adv. Drug Deliv. Rev. 2006, 58 (15), 1655-1670.

(21) Kotsuchibashi, Y.; Ebara, M.; Aoyagi, T.; Narain, R. Recent Advances in Dual Temperature Responsive Block Copolymers and Their Potential as Biomedical Applications. Polymers (Basel). 2016, 8 (11).

(22) Longenecker, R.; Mu, T.; Hanna, M.; Burke, N. A. D.; Stöver, H. D. H. Thermally Responsive 2Hydroxyethyl Methacrylate Polymers: Soluble-Insoluble and Soluble-Insoluble-Soluble Transitions. Macromolecules 2011, 44 (22), 8962-8971.

(23) Karjalainen, E.; Aseyev, V.; Tenhu, H. Upper or Lower Critical Solution Temperature, or Both? 
Studies on Cationic Copolymers of N-Isopropylacrylamide. Polym. Chem. 2015, 6 (16), 30743082.

(24) Niskanen, J.; Vapaavuori, J.; Pellerin, C.; Winnik, F. M.; Tenhu, H. Polysulfobetaine-Surfactant Solutions and Their Use in Stabilizing Hydrophobic Compounds in Saline Solution. Polymer. $2017,127,77-87$.

(25) Ihsan, A. Bin; Sun, T. L.; Kurokawa, T.; Karobi, S. N.; Nakajima, T.; Nonoyama, T.; Roy, C. K.; Luo, F.; Gong, J. P. Self-Healing Behaviors of Tough Polyampholyte Hydrogels. Macromolecules 2016, 49 (11), 4245-4252.

(26) La, T.-G.; Li, X.; Kumar, A.; Fu, Y.; Yang, S.; Chung, H.-J. Highly Flexible, Multipixelated Thermosensitive Smart Windows Made of Tough Hydrogels. ACS Appl. Mater. Interfaces 2017, 9 (38), 33100-33106.

(27) Nizardo, N.; Schanzenbach, D.; Schönemann, E.; Laschewsky, A.; Nizardo, N. M.; Schanzenbach, D.; Schönemann, E.; Laschewsky, A. Exploring Poly(Ethylene Glycol)-Polyzwitterion Diblock Copolymers as Biocompatible Smart Macrosurfactants Featuring UCST-Phase Behavior in Normal Saline Solution. Polymers (Basel). 2018, 10 (3), 325.

(28) Plamper, F. A.; McKee, J. R.; Laukkanen, A.; Nykänen, A.; Walther, A.; Ruokolainen, J.; Aseyev, V.; Tenhu, H. Miktoarm Stars of Poly(Ethylene Oxide) and Poly(Dimethylaminoethyl Methacrylate): Manipulation of Micellization by Temperature and Light. Soft Matter 2009, 5 (9), 1812.

(29) Haladjova, E.; Mountrichas, G.; Pispas, S.; Rangelov, S. Poly(Vinyl Benzyl Trimethylammonium Chloride) Homo and Block Copolymers Complexation with DNA. J. Phys. Chem. B 2016, 120 (9), 
$2586-2595$.

(30) Prabhu Charan, K. T.; Pothanagandhi, N.; Vijayakrishna, K.; Sivaramakrishna, A.; Mecerreyes, D.; Sreedhar, B. Poly(Ionic Liquids) as "Smart" Stabilizers for Metal Nanoparticles. Eur. Polym. J. $2014,60,114-122$.

(31) Ward, M. A.; Georgiou, T. K.; Ward, M. A.; Georgiou, T. K. Thermoresponsive Polymers for Biomedical Applications. Polymers (Basel). 2011, 3 (3), 1215-1242.

(32) Cardoso, A. M.; Calejo, M. T.; Morais, C. M.; Cardoso, A. L.; Cruz, R.; Zhu, K.; Pedroso De Lima, M. C.; Jurado, A. S.; Nyström, B. Application of Thermoresponsive PNIPAAM-b-PAMPTMA Diblock Copolymers in SiRNA Delivery. Mol. Pharm. 2014, 11 (3), 819-827.

(33) Zhang, Y.; Tang, H.; Wu, P. Multiple Interaction Regulated Phase Transition Behavior of ThermoResponsive Copolymers Containing Cationic Poly(lonic Liquid)S. Phys. Chem. Chem. Phys. 2017, 19 (45), 30804-30813.

(34) Andersson, T.; Holappa, S.; Aseyev, V.; Tenhu, H. Complexation of Linear and Poly(Ethylene Oxide)-Grafted Poly(Methacryl Oxyethyl Trimethylammonium Chloride) with Poly(Ethylene Oxide-Block-Sodium Methacrylate). J. Polym. Sci. Part A Polym. Chem. 2003, 41 (13), 19041914.

(35) Kou, R.; Zhang, J.; Wang, T.; Liu, G. Interactions between Polyelectrolyte Brushes and Hofmeister lons: Chaotropes versus Kosmotropes. Langmuir 2015, 31 (38), 10461-10468.

(36) Xiaohui, W.; Xingping, Q.; Wu, C. Comparison of the Coil-to-Globule and the Globule-to-Coil Transitions of a Single Poly(N-Isopropylacrylamide) Homopolymer Chain in Water. 
Macromolecules 1998, 31 (9), 2972-2976.

(37) Hebbeker, P.; Steinschulte, A. A.; Schneider, S.; Plamper, F. A. Balancing Segregation and Complexation in Amphiphilic Copolymers by Architecture and Confinement. Langmuir 2017, 33 (17), 4091-4106.

(38) Spěváček, J.; Konefał, R.; Čadová, E. NMR Study of Thermoresponsive Block Copolymer in Aqueous Solution. Macromol. Chem. Phys. 2016, 217 (12), 1370-1375.

(39) Spěváček, J.; Konefał, R.; Dybal, J.; Čadová, E.; Kovářová, J. Thermoresponsive Behavior of Block Copolymers of PEO and PNIPAm with Different Architecture in Aqueous Solutions: A Study by NMR, FTIR, DSC and Quantum-Chemical Calculations. Eur. Polym. J. 2017, 94, 471-483.

(40) Sullivan, M. R.; Yao, W.; Tang, D.; Ashbaugh, H. S.; Gibb, B. C. The Thermodynamics of Anion Complexation to Nonpolar Pockets. J. Phys. Chem. B 2018, 122 (5), 1702-1713. 


\section{Polycation-PEG block copolymer undergoes step-wise phase separation}

process in aqueous triflate solution

Vikram Baddam, Vladimir Aseyev, Sami Hietala, Erno Karjalainen and Heikki Tenhu

\section{Graphical abstract}

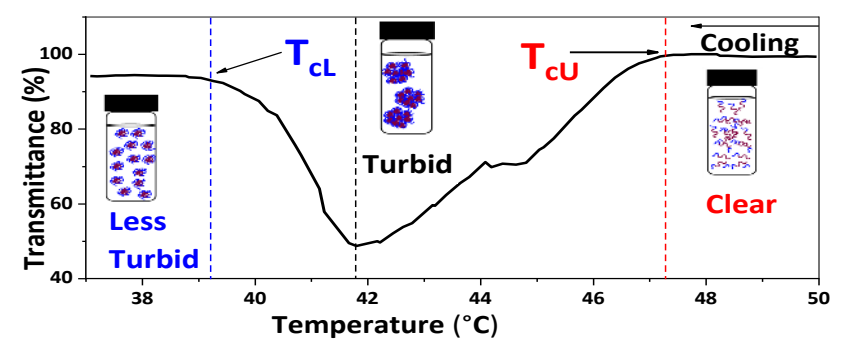




\title{
Supporting information
}

\section{Polycation-PEG block copolymer undergoes step-wise phase separation in aqueous triflate solutions}

\author{
Vikram Baddam, Vladimir Aseyev, Sami Hietala, Erno Karjalainen and Heikki Tenhu* \\ Department of Chemistry, PB 55, FIN-00014 University of Helsinki, Finland
}

*Corresponding author

Heikki Tenhu, Department of Chemistry, University of Helsinki, PB 55, FIN-00014, Finland.

heikki.tenhu@helisnki.fi 


\section{Syntheses}

\section{Monomer (vinyl benzyl)trimethylammonium trifluoromethanesulfonate VBTMA-OTf}

In the reaction flask, $20.15 \mathrm{~g}(0.095 \mathrm{~mol})$ of (VBTMA) Cl in $100 \mathrm{~mL}$ of acetonitrile and $21.29 \mathrm{~g}(0,136 \mathrm{~mol})$ LiOTf in $70 \mathrm{~mL}$ of acetonitrile were added. The reaction mixture was kept stirring overnight at room temperature. After phase separation, the organic phase was concentrated by evaporating the solvent. Then the monomer was precipitated into diethyl ether three times to obtained white solid crystal product. The monomer was dried under vacuum and then analyzed with ${ }^{19} \mathrm{~F}$ NMR and ${ }^{1} \mathrm{H}$ NMR spectroscopy. The yield was $23.49 \mathrm{~g}$.

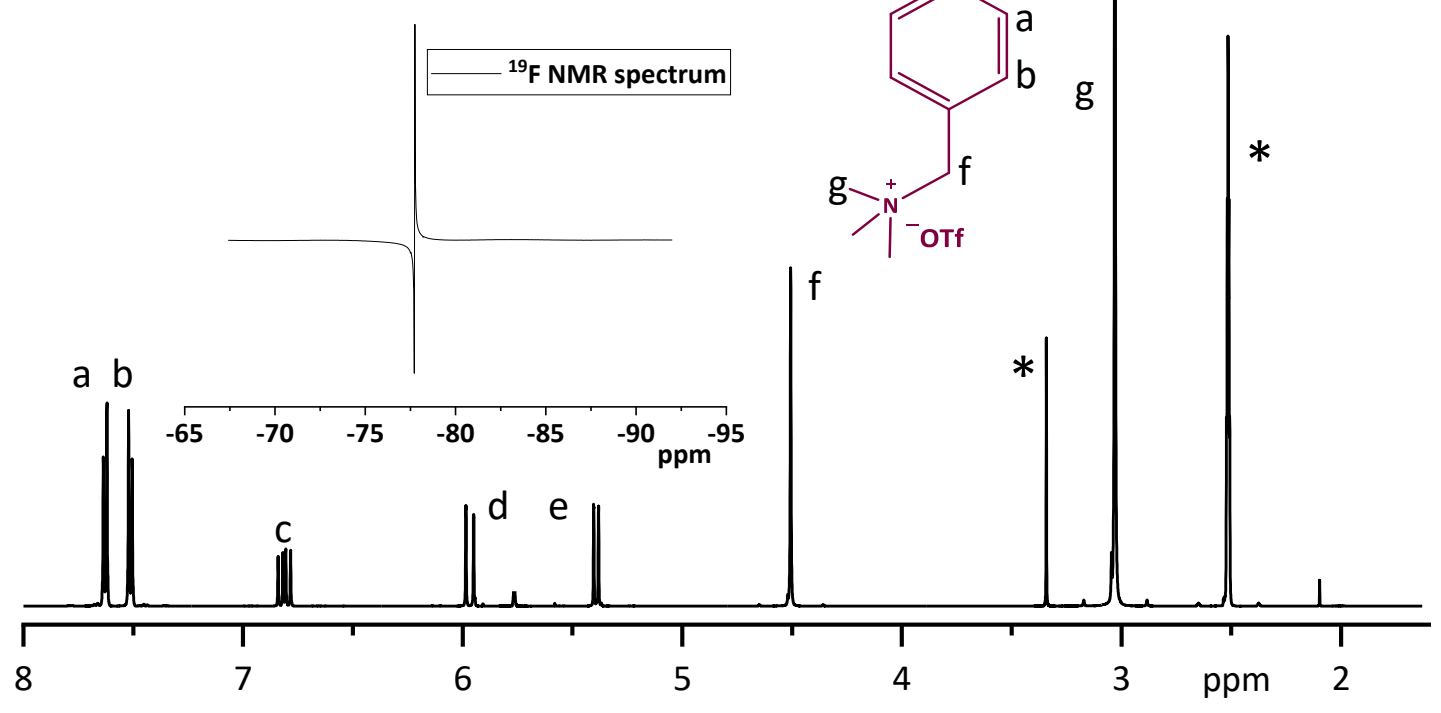

Figure S1. ${ }^{1} \mathrm{H}$ NMR and ${ }^{19} \mathrm{~F}$ NMR spectra of monomer VBTMA-OTf in DMSO-d $\mathrm{d}_{6}$.

\section{Poly (vinyl benzyl) trimethylammonium trifluoromethanesulfonate PVBTMA-OTf}

Monomer VBTMA-OTf (0.502 g, 1.59 mmol, 100 equiv) in $6 \mathrm{~mL}$ of water, CPDTC (5.311 mg, $0.015 \mathrm{mmol}, 1$ equiv), ACPA $(0.86 \mathrm{mg}, 0.0031 \mathrm{mmol}, 0.1$ equiv) in $1 \mathrm{~mL}$ of methanol were added to a reaction flask, which was equipped 
with a stir bar and sealed with a rubber septum. After purging with nitrogen gas for 40 min, the reaction mixture was stirred in a preheated oil bath at $75^{\circ} \mathrm{C}$ for $23 \mathrm{~h}$. The polymerization was stopped by quenching the reaction with liquid nitrogen. The pure homopolymer was obtained from reaction solution by dialysis against watermethanol mixtures.

\section{Synthesis of diblock copolymer PEG-b-PVBTMA-OTf}

Synthesis of diblock copolymer PEG-b-PVBTMA-OTf was conducted as follows. To the $0.507 \mathrm{~g}$ (1.55 mmol) of VBTMA OTf monomer in $6 \mathrm{~mL}$ of water, $0.078 \mathrm{~g}$ (0.015 mmol) of PEG macro-CTA and $0.87 \mathrm{mg}$ (0.0031 mmol) of ACPA in $1 \mathrm{~mL}$ of methanol were added. The reaction mixture was purged with nitrogen gas for more than 40 minutes and then heated up to $75^{\circ} \mathrm{C}$. After $41 \mathrm{~h}$ reaction time samples from hot reaction mixture were collected for the determination of conversion. Then the mixture was immersed into liquid nitrogen to stop the reaction. The reaction solution was diluted with distilled water and transferred to dialysis tubing. The mixture was dialyzed against water and water/methanol mixtures for 3 days and freeze dried.

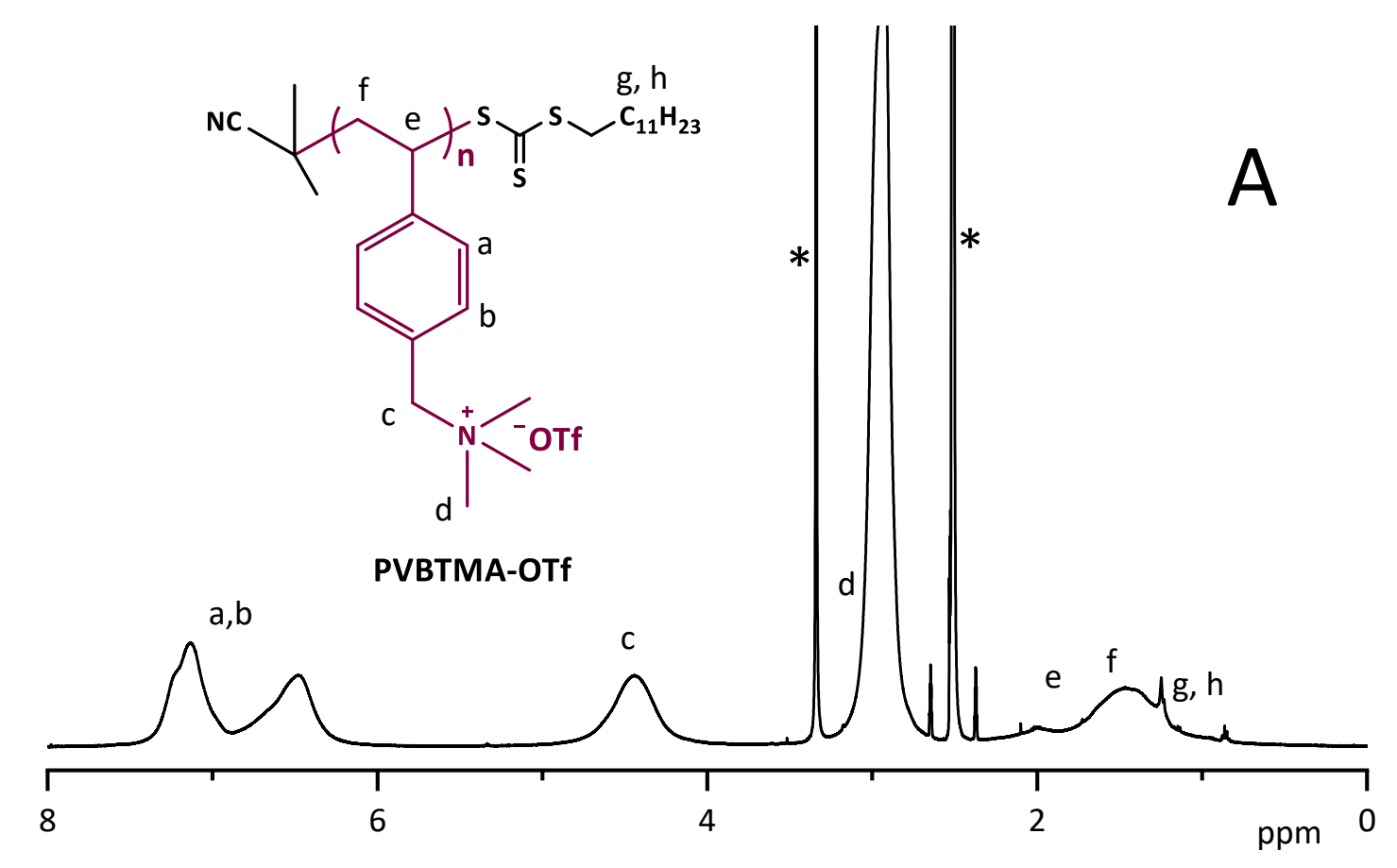




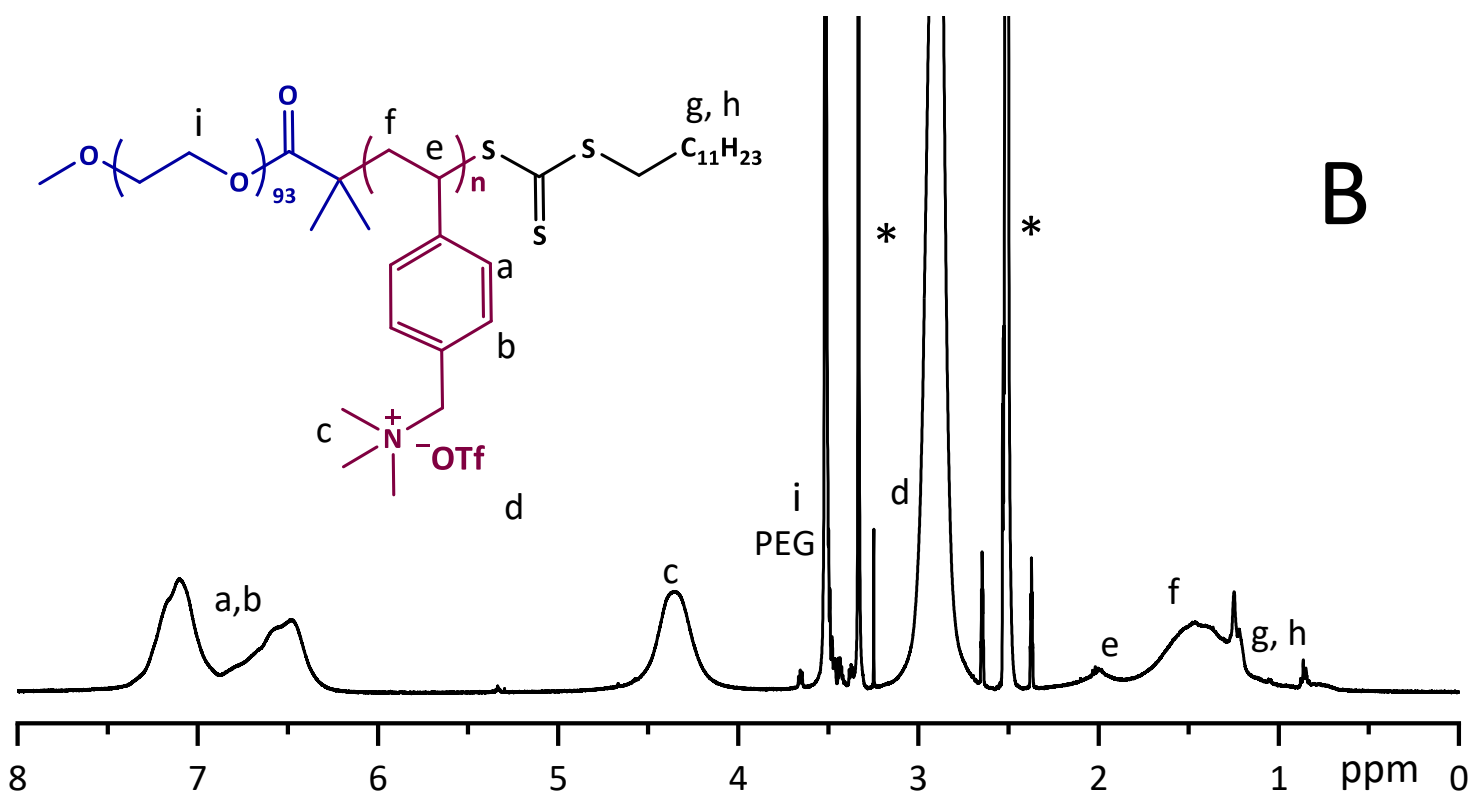

Figure S2. ${ }^{1} \mathrm{H}$ NMR spectra of $(A)$ homo and (B) diblock copolymers of VBTMA-OTf in DMSO-d 6 .

Phase separation of homo and diblock copolymer
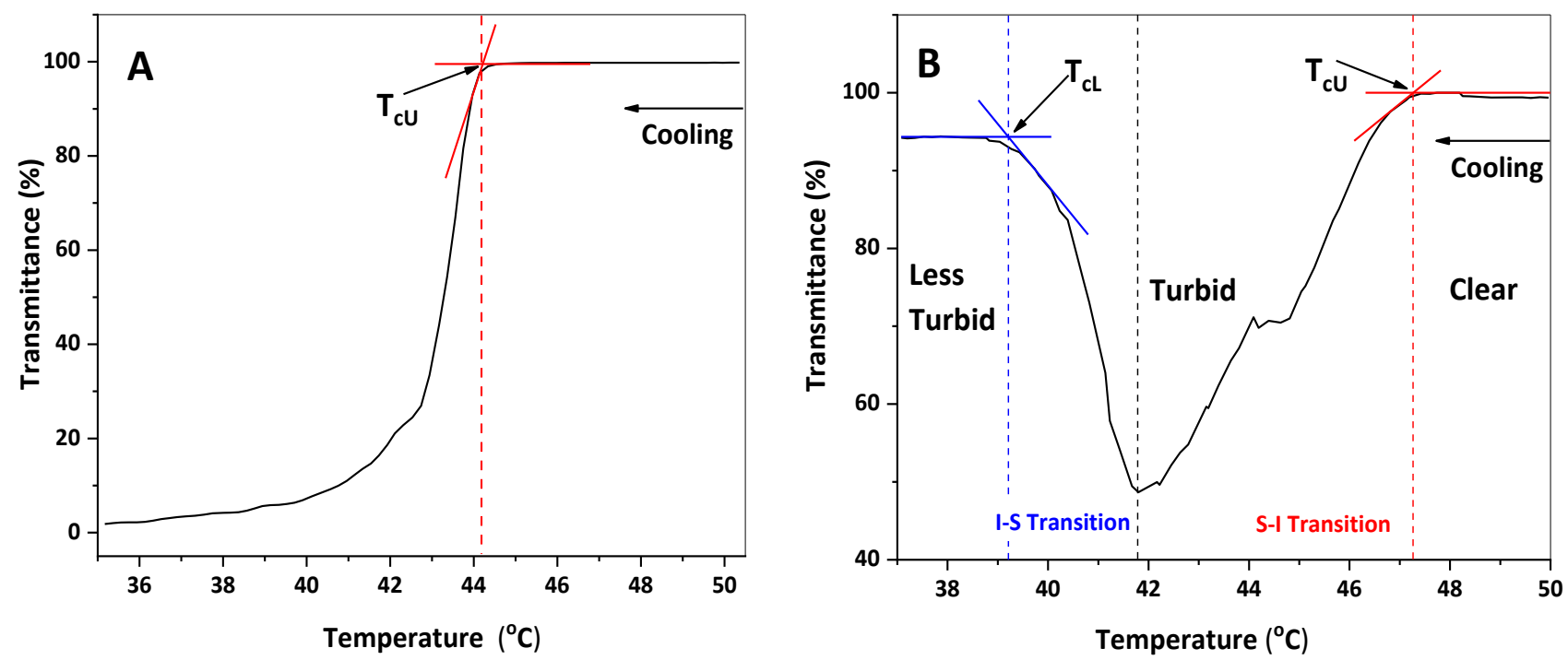

Figure S3. Determination of the cloud point temperatures $T_{C U}$ and $T_{C L}$ from the cooling curves of $(A)$ homo; and (B) block copolymers. 


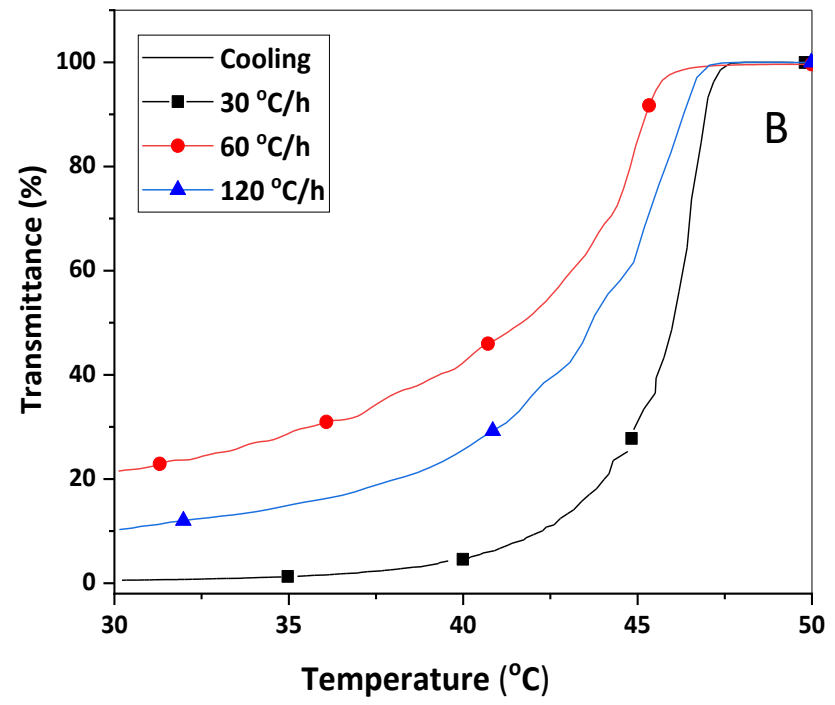

Figure S4. Transmittance curves for PVBTMA-OTf (1 $\mathrm{mg} \mathrm{mL}^{-1}$ with $30 \mathrm{mM}$ LiOTf) with different cooling rates.

\section{Block copolymer PEG-b-PVBTMA-OTf}

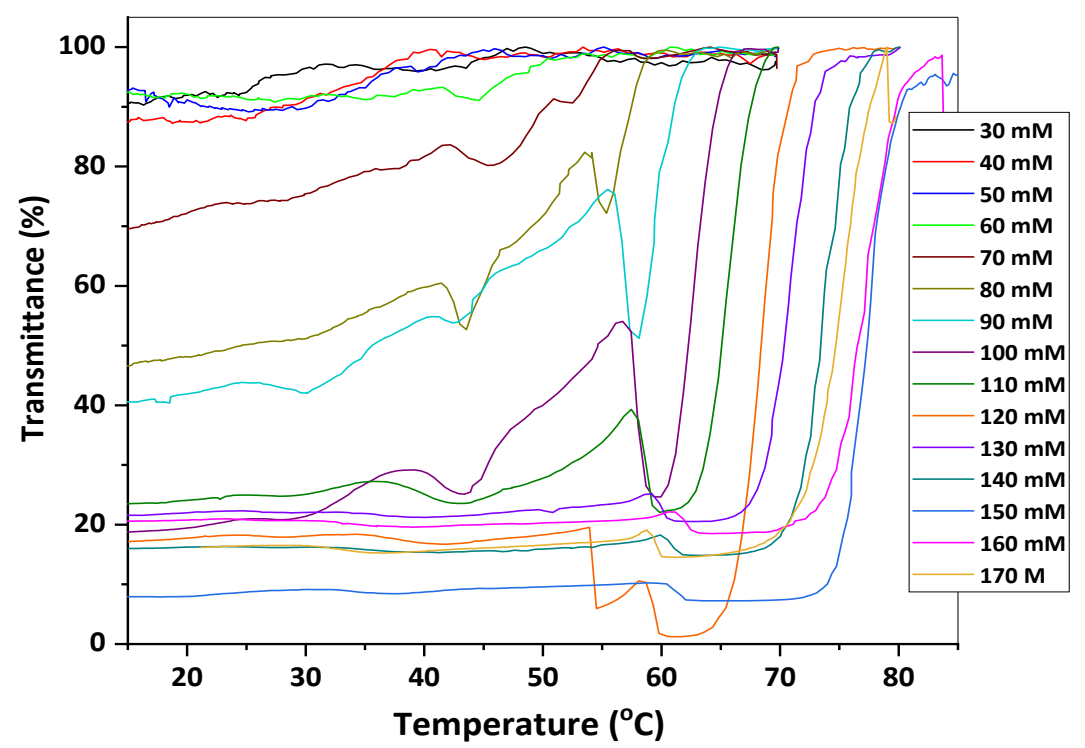

Figure S5. Transmittance curves for $1 \mathrm{mg} \mathrm{mL}^{-1}$ PEG-b-PVBTMA-OTf polymer solutions with various LiOTf salt concentrations as a function of temperature. Cooling scans on the left and heating scans on the right. 


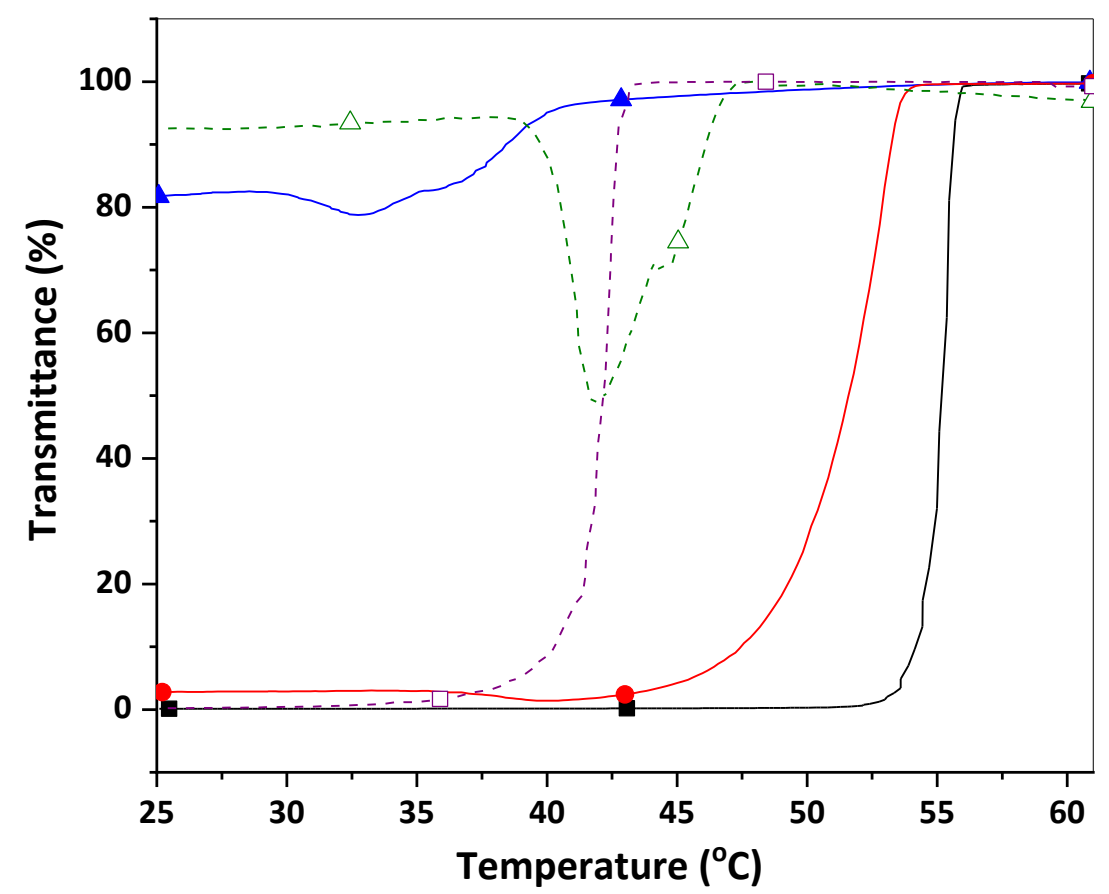

Figure S6. Cooling curves for a mixed solution of PEG-mCTA $\left(0.36 \mathrm{mg} \mathrm{mL}^{-1}\right)$ and PVBTMA-OTf $\left(1.64 \mathrm{mg} \mathrm{mL}^{-1}\right)$ in $50 \mathrm{mM}$ LiOTf (black, $\mathbf{m})$, a mixed solution of PEG and the diblock copolymer $\left(0.178 \mathrm{mg} \mathrm{mL}^{-1}\right.$ and $1 \mathrm{mg} \mathrm{mL}^{-1}$ in 50mM LiOTf solution) (blue, $\boldsymbol{\Delta})$, a mixed solution of homo and diblock copolymer $\left(0.2 \mathrm{mg} \mathrm{mL}^{-1}\right.$ and $1 \mathrm{mg} \mathrm{mL}^{-1}$ in $50 \mathrm{mM}$ LiOTf solution) (red, $\bullet$ ), PEG-PVBTMA (2 $\mathrm{mg} \mathrm{mL}^{-1}$ in $50 \mathrm{mM}$ LiOTf solution) (green, $\Delta$, from Figure 4),

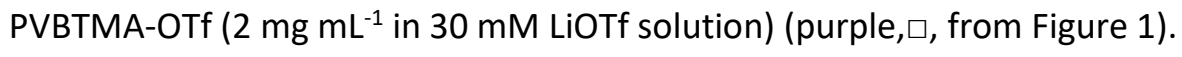




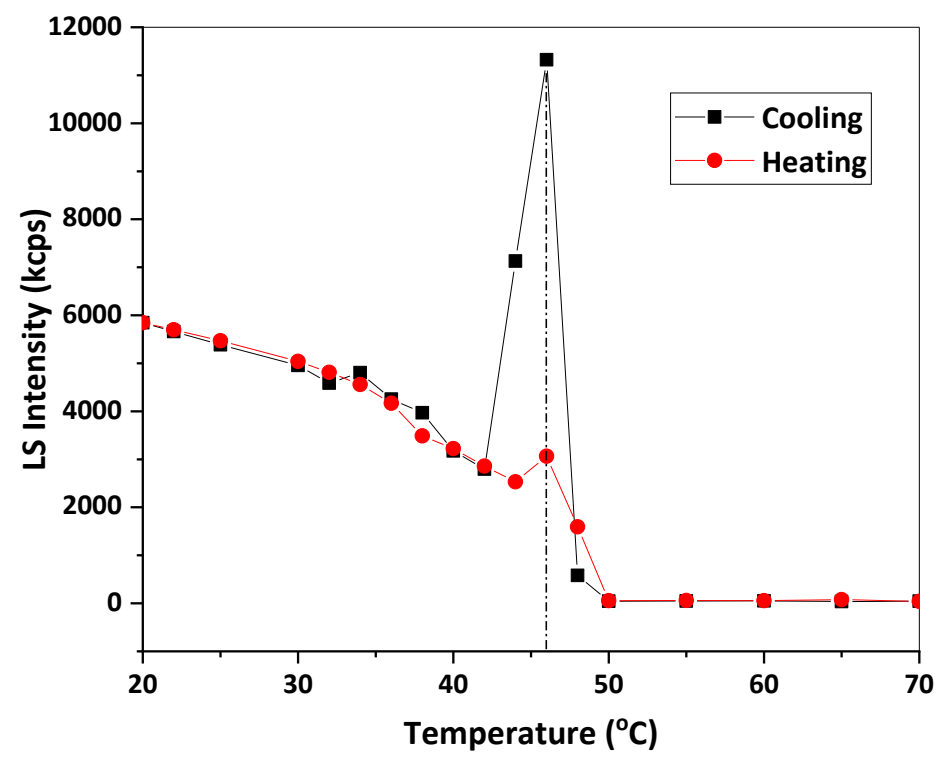

Figure S7. Intensity of light scattered at $173^{\circ}$ angle plotted for PEG-b-PVBTMA -OTf $2 \mathrm{mg} \mathrm{mL}^{-1}$ solution with 50 mM LiOTf (vs. temperature and measures step-wise using ZetaSizer first upon cooling (black line) and then upon heating (red line). The sample was equilibrated at each temperature for 3 minutes.

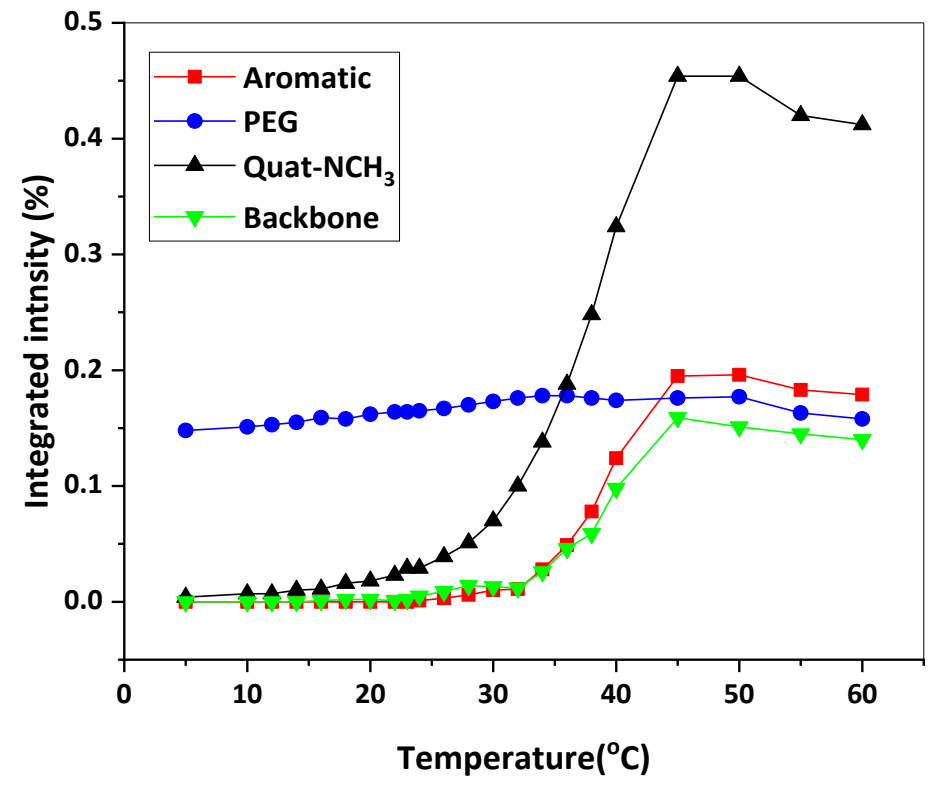

Figure S8. Integrated intensities of the NMR signals. Water signal was used as a reference. 